Chapman University

Chapman University Digital Commons

Pharmacy Faculty Articles and Research

School of Pharmacy

2014

\title{
Advances in Functionalized Ionic Liquids as Reagents and Scavengers in Organic Synthesis
}

Manoj Kumar Muthyala

Birla Institute of Technology and Science

Kavya Velisetti

Birla Institute of Technology and Science

Keykavous Parang

Chapman University, parang@chapman.edu

Anil Kumar

Birla Institute of Technology \& Science

Follow this and additional works at: http://digitalcommons.chapman.edu/pharmacy_articles

Part of the Organic Chemistry Commons

\section{Recommended Citation}

Muthyala, M. K. Velisetti, K., Parang, K., Kumar, A. K. Advances in functionalized ionic liquids as reagents and scavengers in organic synthesis. Current Org. Chem. (2014) 18, 2530-2554.

doi: $10.2174 / 138527281819141028114639$

This Article is brought to you for free and open access by the School of Pharmacy at Chapman University Digital Commons. It has been accepted for inclusion in Pharmacy Faculty Articles and Research by an authorized administrator of Chapman University Digital Commons. For more information, please contact laughtin@chapman.edu. 


\section{Advances in Functionalized Ionic Liquids as Reagents and Scavengers in Organic Synthesis}

\section{Comments}

This is a pre-copy-editing, author-produced PDF of an article accepted for publication in Current Organic Chemistry, volume 18, 2014 following peer review. The definitive publisher-authenticated version is available online at DOI: 10.2174/138527281819141028114639.

\section{Copyright}

Bentham Science Publishers 


\title{
Advances in Functionalized Ionic Liquids as Reagents and Scavengers in Organic Synthesis
}

\author{
Manoj Kumar Muthyala, ${ }^{a}$ Kavya Velisetti, ${ }^{a}$ Keykavous Parangb," and Anil Kumar, ${ }^{a}$, \\ ${ }^{a}$ Department of Chemistry, Birla Institute of Technology and Science, Pilani 333 031, Rajasthan, India \\ ${ }^{b}$ Chapman University School of Pharmacy, Irvine, California 92618, USA
}

\begin{abstract}
Functionalized ionic liquids (FILs) synthesized with specific desired chemical properties have shown promising results in various areas of organic synthesis. In supported organic synthesis, FILs have become known as a new alternative to commonly used PEG and fluorous soluble supports. This review summarizes the progress of recent development in the synthesis of functionalized ionic liquids with emphasis on their applications as reagents and scavengers in organic synthesis.
\end{abstract}

Keywords: Supported reagents, ionic liquid, functionalized ionic liquid, reagents, scavenger and soluble support

\section{Introduction}

Supported materials have facilitated the organic synthetic process by virtue of their inimitable advantages, such as facile separation and purification of products and making the process environmentally friendly by increasing reusability and recyclability. This branch of chemistry has become a boon to pharmaceutical companies by assisting them to find the new drugs rapidly for high-throughput screening technologies, thus saving a significant amount of money and ultimately changing their fundamental approach towards drug discovery.

Solid-phase organic synthesis (SPOS) is a widely used technique in organic synthesis for the preparation of libraries of molecules for various purposes. ${ }^{1-11}$ The advantages of this strategy have been thoroughly described in the literature. Merrifield pioneered the concept of solid phase synthesis to attain an efficient method for the synthesis of polypeptides. ${ }^{12}$ This method was successfully applied for the synthesis of biopolymers such as DNA, RNA and peptides, as the chemistry required for chain extension is consistent for each step. Later, SPOS proved to be an efficient technique in combinatorial synthesis that facilitated the synthesis of many pharmacologically important compounds and made the purification process more facile. ${ }^{8,13-16}$ A broad range of polymer-supported materials ${ }^{1-11,} 17$ and silica-supported materials ${ }^{18-20}$ have been developed for SPOS. Despite its great success, SPOS suffers from some serious drawbacks, such as inability to purify and characterize the compounds prior to the final cleavage from the solid support, heterogeneous reaction conditions and non-linear kinetics.

To overcome these drawbacks soluble supports such as $\mathrm{PEG}^{21-26}$ and fluorous phase ${ }^{27-31}$ were utilized as an alternative to the solid phase. The reactions using these soluble supports are performed under conventional solution phase conditions. Another interesting feature of PEG supports is that a change in the polarity of the solvent leads to precipitation of the support, thus resulting in facile separation by filtration after the completion of the reaction. PEG-supported synthesis often combines the advantage of both product isolation and purification of solid-phase chemistry with the solubility benefits of solution phase chemistry. However, maximum loading capacity of a PEG support is $<1 \mathrm{mmol}$ that is even lower than that of polystyrene-supported reagents. ${ }^{15,32-35}$ Moreover, due to its high oxygenating ability, PEG may interfere in certain types of reactions that may lead to degeneration of the support. In case of fluorous-supported synthesis, special solvents requirement and cost are some serious concerns. ${ }^{36,37}$ Thus, search of new soluble support led to the development of ionic liquid as alternative soluble support to PEG and fluorous supports in the last decade. ${ }^{38,39}$ In view of their unique characteristics, ionic liquid-supported reagents and catalyst have attracted great interest both from academia and industry. ${ }^{40}$

Ionic liquids are salts with melting points below the boiling point of water and they are solely composed of ions in their molten state. These materials have been termed as 'designer solvents' as their properties such as thermal stability, vapor pressure, and solvating ability can be tuned by appropriately varying combination of ions. The initial focus of organic chemists has been to use ionic liquids as an alternative to volatile organic compound solvents (VOCs) in various organic transformations. ${ }^{41-45}$

In last decade new class of functionalized ionic liquids (FILs) also known as task-specific ionic liquids (TSILs) have been synthesized with specific desired chemical properties. ${ }^{46-48}$ The functional groups in FILs are covalently tethered to the anion, cation or both to get the desired properties for specific chemical tasks. ${ }^{49-54}$ A plethora of FILs has been synthesized and used as reagents, ${ }^{50,51}$ catalysts, ${ }^{52,53}$ and scavengers ${ }^{55-58}$ in organic synthesis. A number of excellent reviews have appeared on FILs dealing with ionic liquid-supported catalysis. ${ }^{45,}$ 59-61 However, review articles on developments of ionic liquid-supported reagents as scavengers are limited. ${ }^{62}$ In this article, we have reviewed the synthesis of ionic liquid-supported reagents and their application as reagents and scavengers in organic synthesis. Synthesis of chiral ionic liquids and ionic liquid-supported catalysts are beyond the scope of this manuscript, and interested readers are directed to some excellent review articles published focusing on this area. ${ }^{63-67}$ 


\section{Ionic liquid-supported reagents}

\subsection{Ionic liquid-supported Swern oxidation reagent}

Swern oxidation is a well known and widely used process for the oxidation of alcohols to the corresponding carbonyl compounds. ${ }^{68,}{ }^{69}$ Dimethyl sulfide, co-product of Swern oxidation process is volatile, noxious, foul-smelling and difficult to recover. To overcome the drawbacks associated with this protocol, Chan and co-workers prepared non-volatile and odourless ionic liquid-supported sulfoxides 6. $^{70}$ Compound 6 was synthesized by simple reaction sequences as shown in Scheme 1. Alkylation of 1,2-dimethylimidazole $\mathbf{1}$ with bromo alcohols 2 followed by treatment with AgOTf gave ionic liquid-supported alcohols 3, which were subjected to mesylation under basic conditions to give mesylated ionic liquid 4. Sequential reactions involving, treatment of $\mathbf{4}$ with thiourea, followed by base hydrolysis and quenching the reaction mixture with dimethyl sulphate resulted in ionic liquid-supported sulphide 5. Controlled oxidation of $\mathbf{5}$ with periodic acid gave desired ionic liquid-supported sulfoxide 6. Due to the negligible vapor pressure, these newly synthesized ionic liquid-sulfur compounds 5 and $\mathbf{6}$ do not possess odor.

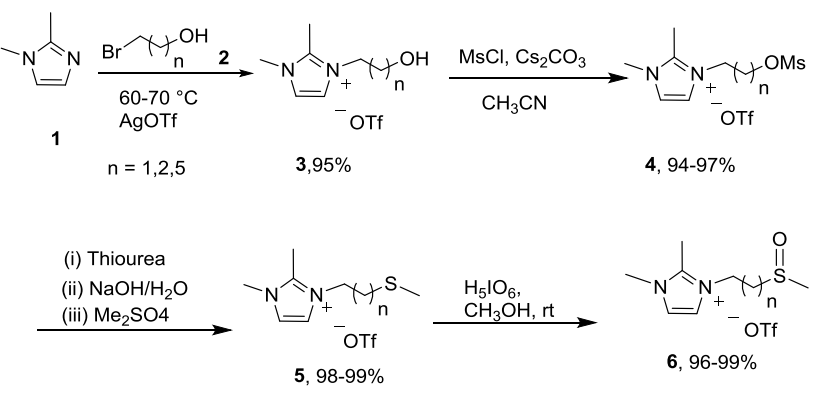

Scheme 1: Synthesis of IL-supported Swern reagent 6.

Alcohols 7 were successfully oxidized to corresponding carbonyl compounds 8 in excellent yields (82-97\%) under the Swern oxidation conditions using 6 (Scheme 2). In addition to the odorless conditions, simple ether extraction, excellent yields, and high purity without the need of chromatographic purification are silent features of the method. Moreover, the recovered $\mathbf{5}$ was regenerated and reused up to four cycles with comparable activity.

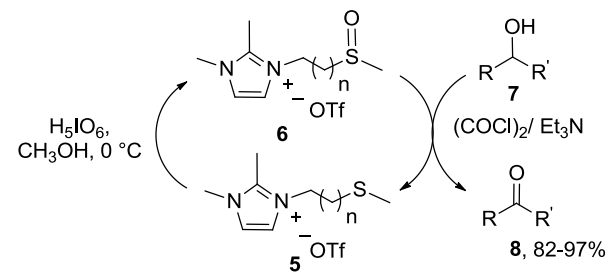

$\mathrm{R}=\mathrm{C}_{6} \mathrm{H}_{5}, 4-\mathrm{BrC}_{6} \mathrm{H}_{4}, \mathrm{C}_{10} \mathrm{H}_{7}, \mathrm{C}_{6} \mathrm{H}_{5} \mathrm{C}_{2} \mathrm{H}_{2}, 3-\mathrm{OBnC}_{6} \mathrm{H}_{4}, 3,4-\left(\mathrm{OCH}_{3}\right)_{2} \mathrm{C}_{6} \mathrm{H}_{3}$ $\mathrm{R}^{\prime}=\mathrm{H}, \mathrm{CH}_{3}, \mathrm{C}_{6} \mathrm{H}_{5}$,

Scheme 2: Oxidation of alcohols using IL-supported Swern reagent 6 .

\subsection{Ionic liquid-supported selenium reagent}

Ying group reported novel ionic liquid-supported selenium reagents 15 to overcome the purification and handling problems encountered with selenium dioxide and organic selenides in the oxidation reactions. ${ }^{71}$ Selenium reagent 15 was synthesized by treating $\mathrm{Na}_{2} \mathrm{Se}_{2}$ with phenyl halide $9 \mathbf{a}$ or benzyl halide $\mathbf{9 b}$ to give dialkyldiselane 11. Reduction of $\mathbf{1 1}$ with $\mathrm{NaBH}_{4}$ followed by reaction with bromochloroalkane 12 gave alkyl hypochloroselenoite $\mathbf{1 3}$, which upon reaction with 1-methylimidazole gave ionic liquid-supported selenium reagent 15 (Scheme 3).

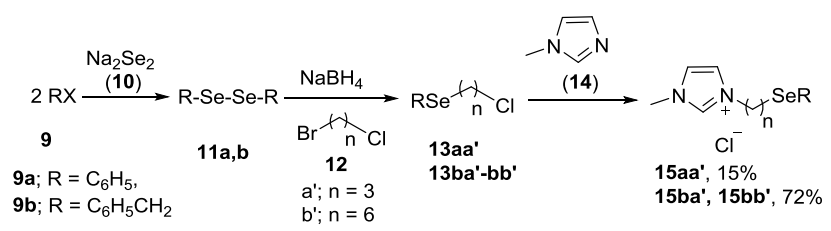

Scheme 3: Synthesis of IL-supported selenium 15.

Reagent $15 \mathbf{b}$ in the presence of two fold excess of $\mathrm{H}_{2} \mathrm{O}_{2}$ oxidized alcohols $\mathbf{7}$ to corresponding carbonyl compounds $\mathbf{8}$ in good to moderate yields (Scheme 4). The conventional solubility difference in reagent $\mathbf{1 5}$ and carbonyl compounds allowed easy isolation of the product from the reaction mixture. In addition to simplifying purification process, $\mathbf{1 5}$ was also recycled and reused effectively up to four times.

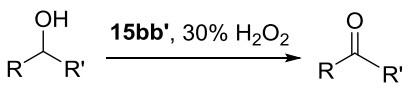

$$
\begin{aligned}
& 7 \quad \mathbf{8}, 32-65 \%
\end{aligned}
$$

$\mathrm{R}=\mathrm{C}_{6} \mathrm{H}_{5}, 4-\mathrm{NO}_{2} \mathrm{C}_{6} \mathrm{H}_{4}, 2-\mathrm{OHC}_{6} \mathrm{H}_{4}, 4-\mathrm{BrC}_{6} \mathrm{H}_{4}, 4-\mathrm{ClC}_{6} \mathrm{H}_{4}$,

$\mathrm{C}_{6} \mathrm{H}_{5} \mathrm{CHCH}, 4-\mathrm{CH}_{3} \mathrm{C}_{6} \mathrm{H}_{4}, \mathrm{C}_{8} \mathrm{H}_{13} . \mathrm{R}^{\prime}=\mathrm{H}, \mathrm{CH}_{3}, \mathrm{C}_{2} \mathrm{H}_{5}, \mathrm{C}_{6} \mathrm{H}_{5}$

Scheme 4: Oxidation of alcohols using IL-supported selenium 15 in the presence of $\mathrm{H}_{2} \mathrm{O}_{2}$.

\subsection{Ionic liquid-supported iodobenzene and hypervalent iodine reagents}

Hypervalent iodine reagents have received great interest in organic synthesis in recent years as they are used to carry out several organic transformations under metal free conditions as well as in the presence of transition metals and their reactivity can be tuned accordingly. ${ }^{72-75}$ With their increasing use in organic transformations, isolation of co-product and reuse of these reagents is a great challenge for synthetic chemists.

\subsubsection{Ionic liquid-supported iodobenzene}

To improve synthetic utility of hypervalent iodine reagents, Togo and co-workers have designed and synthesized several ionic liquid-supported iodobenzenes (Figure 1). ${ }^{76-78}$
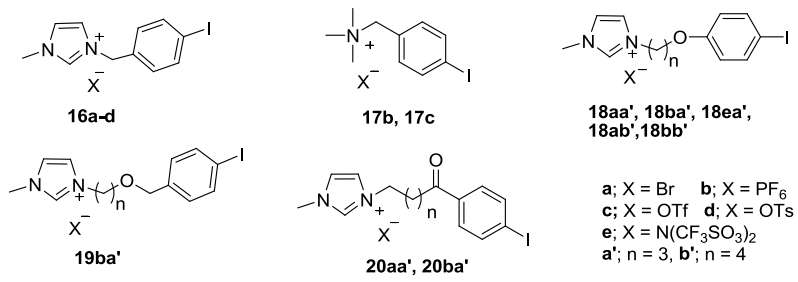

Figure 1: Structures of various IL-supported iodobenzenes. 
Hydroxyl(tosyloxy)iodobenzene (HTIB) also known as Koser's reagent is an excellent reagent for the synthesis of $\alpha$-tosyloxy ketones from ketones. ${ }^{79}$ Togo et al. developed an alternative procedure, in which various ketones 21 were converted into corresponding $\alpha$-tosyloxy ketones 22 using $m$-chloroperbenzoic acid ( $m \mathrm{CPBA}$ ) and $p$-toluenesulfonic acid $(p-\mathrm{TsOH})$ in the presence of a catalytic amount of ionic liquid-supported iodobenzenes 16a, 17, or $\mathbf{2 0}$ (Scheme 5). ${ }^{78}$ The scope of this procedure was further extended by synthesizing 2-methyl-5-phenylthiazole $\mathbf{2 3}$ directly from $\mathbf{2 1}$ without isolating 22 (Scheme 5). The ionic liquid-supported iodobenzenes were recovered and reused for up to three cycles.

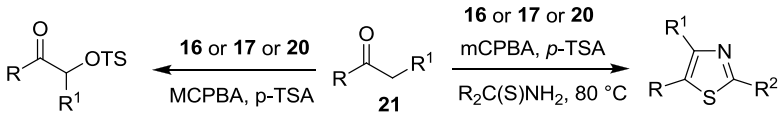

$$
\begin{aligned}
& \text { 22, } 39-82 \% \\
& \mathrm{R}=4-\mathrm{ClC}_{6} \mathrm{H}_{4}, 4-\mathrm{NO}_{2} \mathrm{C}_{6} \mathrm{H}_{4}, 4-\mathrm{CH}_{3} \mathrm{C}_{6} \mathrm{H}_{4} \text {, } \\
& \mathrm{C}_{2} \mathrm{H}_{5}, n-\mathrm{C}_{5} \mathrm{H}_{11} ; \mathrm{R}^{1}=n-\mathrm{C}_{4} \mathrm{H}_{9}, n-\mathrm{C}_{7} \mathrm{H}_{15} \\
& \text { 23, } 37-72 \% \\
& \mathrm{R}=\mathrm{C}_{6} \mathrm{H}_{5} ; \mathrm{R}^{1}=\mathrm{H} ; \mathrm{R}^{2}=\mathrm{CH}_{3}
\end{aligned}
$$

Scheme 5: Synthesis of $\alpha$-tosyloxy ketones and thiazoles using IL-supported iodobenzenes.

Inspired by the in-situ formation of Koser's reagent, Togo and his group developed an efficient cyclization protocol for the synthesis of $N$-methoxy-3,4-dihydro-2,1-benzothiazine -2,2-dioxide derivatives 25 (Scheme 6). ${ }^{76}$ The ionic liquid-supported iodobenzenes $(\mathbf{1 6 b}, \mathbf{1 6 c}$ and 17b) in the presence of $m \mathrm{CPBA}$ and $p$-TsOH catalyzed the cyclization of $\mathrm{N}$-methoxy-2-arylethanesulfonamide derivatives $\mathbf{2 4}$ to give 25. Among various ion supported-iodobenzenes studied in the synthesis of $\mathbf{2 5}, \mathbf{1 6} \mathbf{b}$ and $\mathbf{1 6 c}$ were found to be the more efficient than 16a and 16d. Replacing $p$-TsOH with trifluoroethanol (TFE) gave better yields of $\mathbf{2 5}$ in a shorter period of time. Compound $\mathbf{2 5}$ was further reduced to $\mathbf{2 6}$ using samarium iodide (Scheme 6), however, $p$-methoxy substituted $\mathbf{2 4}$ resulted in spiro-sultam derivatives $\mathbf{2 7}$. Recycling of ionic liquid-supported iodobenzenes showed that the reagents could be recycled and reused for at least five cycles without much loss in its catalytic activity.
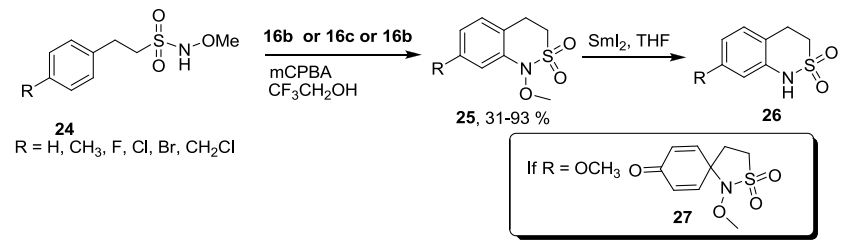

Scheme 6: Cyclization of sulfonamide 24 using 16.

Same group further explored application of $\mathbf{1 6 b}$ or $\mathbf{1 7 b}$ for the cyclization of $N$-methoxy-3-phenylalkanamide 28 to 29 (Scheme 7). Excellent yields of 29 were obtained, and the work-up procedure was quite simple.

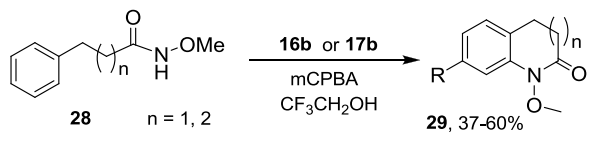

Scheme 7: Cyclization of $N$-methoxy-3-phenylalkanamides using 16 or 17.
Togo group also compared ionic liquid-supported iodobenzene 16b with polymer-supported iodobenzene for the synthesis of 2,4,5-trisubstituted oxazoles $\mathbf{3 5}$ from corresponding ketones $\mathbf{3 1}$ and found that the catalytic activity of ionic liquid-supported iodobenzene is superior over polymer-supported iodobenzene. ${ }^{77}$ The reaction proceeded via in situ generation of trivalent aryliodonium species 30, which in turn reacted with aryl ketones $\mathbf{3 1}$ to form $\beta$-keto-aryliodonium salt 32. Addition of nitrile $\mathbf{3 3}$ to 32 followed by an intermolecular cyclization gave desired oxazoles 35 (Scheme 8).

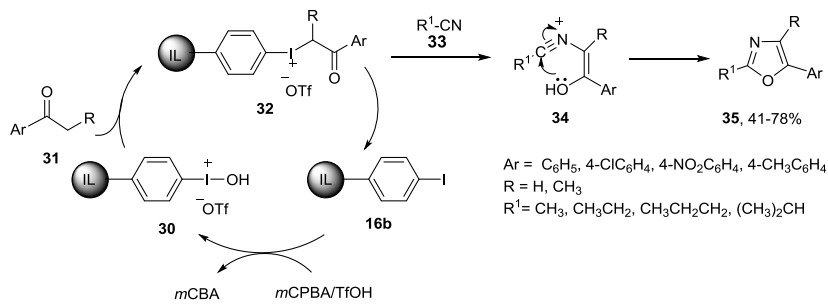

Scheme 8: Proposed mechanism for the synthesis of oxaoles using IL-supported iodobenzene $\mathbf{1 6 b}$

Fuchigami group has reported indirect electrochemical fluorination of active methylene group containing compounds, employing ionic liquid-supported iodobenzene 18ea' as a mediator and $\mathrm{Et}_{3} \mathrm{~N}$.HF as fluoride source. ${ }^{80}$ Fluorination of 36, in the absence of 18ea' (direct electrochemical fluorination) engendered anode passivation and resulted in poorer yields. Whereas employing 18ea' as mediator (indirect electrochemical fluorination) significantly enhanced the product yield and overcame the anode passivation (Scheme 9). The reason for enhanced activity was attributed to the lesser mobility of ionic liquid-supported iodobenzene 18ea' in $\mathrm{Et}_{3} \mathrm{~N}$.HF, which enabled the fluorination effectively. The procedure was further extended to cyclic dithioacetals $\mathbf{3 8}$ to get corresponding fluorinated product 39 (Scheme 9). Simple ether extraction gave the products in pure form. It was found that 18ea' remains intact with $\mathrm{Et}_{3} \mathrm{~N}$.HF and can be reused several times without apparent loss in its activity.
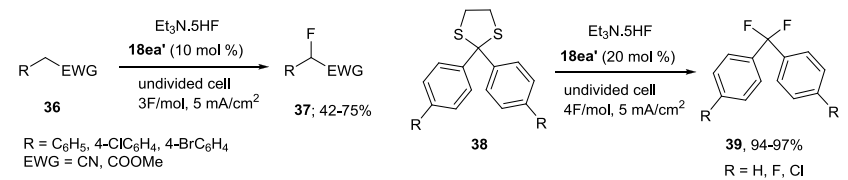

Scheme 9: Electrochemical fluorination using IL-supported iodobenzene 18ea'.

\subsubsection{Ionic liquid-supported iodobenzene diacetate}

Zhang group synthesized ionic liquid-supported iodobenzene diacetate 41 by reacting 4 -iodobenzylbromide 40 with 1-methylimidazole 14 at $80{ }^{\circ} \mathrm{C}$ followed by anion exchange with $\mathrm{BF}_{4}^{-}$and oxidation with peracetic acid (Scheme 10). ${ }^{81}$ They further explored the application of $\mathbf{4 1}$ for the oxidation of alochols $\mathbf{7}$ to ketones $\mathbf{8}$ in ionic liquid [emim] $\left[\mathrm{BF}_{4}\right]$. The oxidation of alcohols $\mathbf{7}$ is believed to be catalyzed by some excess bromide ions present in the [emim] $\left[\mathrm{BF}_{4}\right]$ ionic liquid (Scheme 11). 


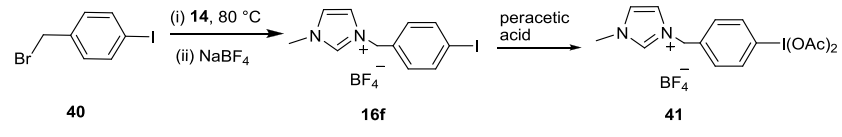

Scheme 10: Synthesis of IL-supported iodobenzene diacetate 41

The investigators believed that bromide ions were oxidized by the ionic liquid-supported reagent $\mathbf{4 1}$ to form an extremely reactive bromonium ion $\left(\mathrm{Br}^{+}\right)$intermediate which then oxidized the alcohol to its corresponding carbonyl compound. Formation of 2,3-dibromo-3-phenyl propanol 44 from cinnamyl alcohol instead of cinnamaldehyde supported formation of $\mathrm{Br}^{+}$ions in the reaction mixture (Scheme 11). The method provides a high degree of selectivity along with easy workup and the reusability of the reagent. By comparing the reactivities of $\mathbf{4 1}$ with $\mathrm{PhI}(\mathrm{OAc})_{2}$, it was found that $\mathbf{4 1}$ gives better yields in shorter reaction time. The improved activity is attributed due to the electron withdrawing nature of imidazolium ions. Additionally, the presence of the $[\mathrm{emim}]\left[\mathrm{BF}_{4}\right]$ solvent is believed to have prevented the over oxidation of primary alcohols to carboxylic acids.

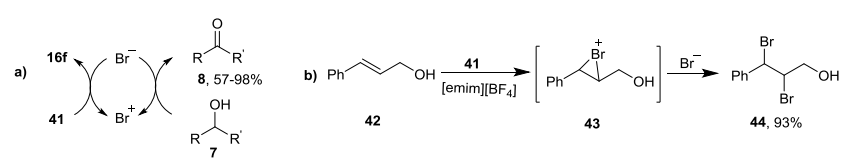

Scheme 11: a) Oxidation of alcohols to carbonyl compounds using 41 b) Reaction of cinnamyl alcohol with 41.

Qian et al. reported oxidation of sulphides $\mathbf{4 5}$ to sulfoxides 46 using ionic liquid-supported iodobenzene diacetate 41 (Scheme 12). ${ }^{82}$ Reagent 41 selectively oxidized sulfides $\mathbf{4 5}$ to the corresponding sulfoxides $\mathbf{4 6}$ in excellent yields at room temperature with high tolerance of various functional groups such as ester, nitrile, methoxy, hydroxyl and alkenes. Of the various solvents screened for the reaction, water was found to be the best choice in terms of the yield and reaction time. It is believed that the phase transfer property of reagent $\mathbf{4 1}$ facilitated the solubility of substrates in water and thus accelerated the reaction.

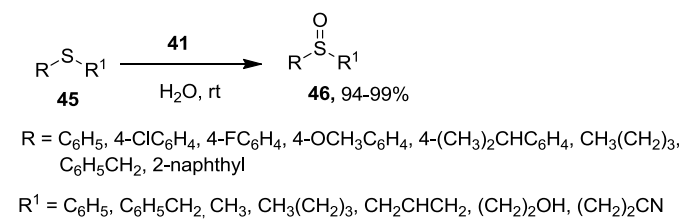

Scheme 12: Oxidation of sulphides to sulfoxides using IL-supported iodobenzene diacetate $\mathbf{4 1}$.

Bao group demonstrated oxidative amidation of aldehydes using 41 (Scheme 13) ${ }^{83}$ Although, the yield of amides 49 were found to be lower than those obtained by the conventional reagent $\mathrm{PhI}(\mathrm{OAc})_{2}$ but easy separation of products and recyclability were inherent advantages of this protocol.

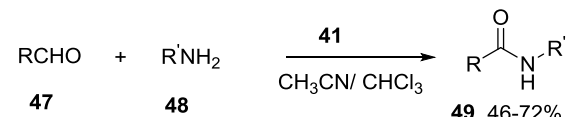

$\mathrm{R}=\mathrm{C}_{6} \mathrm{H}_{5}, 4-\mathrm{ClC}_{6} \mathrm{H}_{4}, 2-\mathrm{ClC}_{6} \mathrm{H}_{4}, 4-\mathrm{BrC}_{6} \mathrm{H}_{4}, 4-\mathrm{IC}_{6} \mathrm{H}_{4}, 4-\mathrm{OCH}_{3} \mathrm{C}_{6} \mathrm{H}_{4}, 4-\mathrm{CH}_{3} \mathrm{C}_{6} \mathrm{H}_{4}$,

3,4,5-( $\left(\mathrm{OCH}_{3}\right)_{3} \mathrm{C}_{6} \mathrm{H}_{2}, 4-\mathrm{NO}_{2} \mathrm{C}_{6} \mathrm{H}_{4}, 3-\mathrm{NO}_{2} \mathrm{C}_{6} \mathrm{H}_{4}$, 1-naphthyl

$\mathrm{R}^{\prime}=\mathrm{CH}_{3}\left(\mathrm{CH}_{2}\right)_{2}, \mathrm{CH}_{3}\left(\mathrm{CH}_{2}\right)_{3}, \mathrm{C}_{6} \mathrm{H}_{5} \mathrm{CH}_{2}$

Scheme 13 Synthesis of amides from aldehydes and amines using IL-supported iodobenzene diacetate $\mathbf{4 1}$.

Togo and co-workers synthesized new class of ionic liquid-supported iodobenzene diacetates 53 and 54 from 4-iodophenol as shown in scheme $14 .^{84}$ The reaction of 4-iodophenol 50 with 1-bromo-3-propanol 2 in the presence of $\mathrm{K}_{2} \mathrm{CO}_{3}$ and $\mathrm{KI}$ afforded $\mathbf{5 1}$, which upon tosylation gave 52. Reaction of $\mathbf{5 2}$ with $N$-methylpyrrolidine followed by oxidation with $m$ CPBA gave $\mathbf{5 4}$ in excellent yields. In an approach, reaction of $\mathbf{5 2}$ with dimethylamine followed by methylation with $\mathrm{TsOCH}_{3}$ and controlled oxidation with $m$ CPBA gave 53 in excellent yields (Scheme 14).

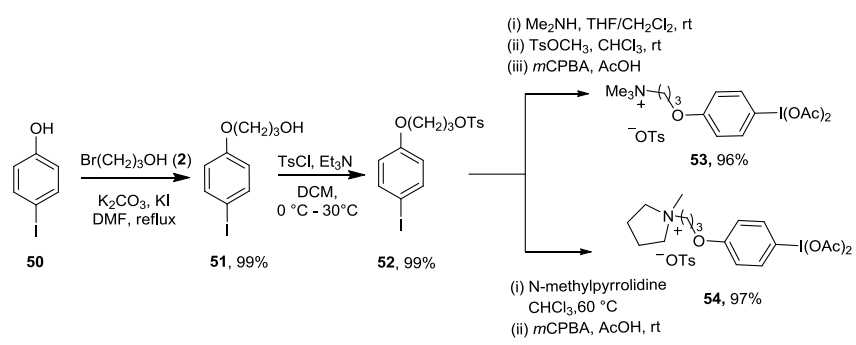

Scheme 14: Synthesis of IL-supported iodobenzene diacetates $\mathbf{5 3} \& \mathbf{5 4}$.

Reagents $\mathbf{5 3}$ and $\mathbf{5 4}$ were used for the oxidation of alcohols 7 to carbonyl compounds $\mathbf{8}$ in the presence of catalytic amounts of 2,2,6,6-tetramethylpiperidin-1-oxyl (TEMPO) and oxidation of $\mathrm{N}, \mathrm{N}$-diisopropylbenzylamines to aromatic aldehydes (Scheme 15).

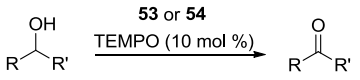

$$
\begin{aligned}
& 7 \quad \mathbf{8}, 81-99 \% \\
& \mathrm{R}, \mathrm{R}^{\prime}=\text { Alkyl, aryl }
\end{aligned}
$$$$
\overbrace{55} \frac{53 \text { or } 54}{\mathrm{NaHCO}_{3}, \mathrm{CHCl}_{3},} \underset{40 . \mathrm{C}}{\mathrm{ArCHO}}
$$$$
\begin{aligned}
\mathrm{Ar}= & \mathrm{C}_{6} \mathrm{H}_{5}, 4-\mathrm{NO}_{2} \mathrm{C}_{6} \mathrm{H}_{4}, 4-\mathrm{CH}_{3} \mathrm{C}_{6} \mathrm{H}_{4}, 4-\mathrm{OCH}_{3} \mathrm{C}_{6} \mathrm{H}_{4}, \\
& 4-\mathrm{BrC}_{6} \mathrm{H}_{4}, 4-\mathrm{MeO}_{2} \mathrm{CC}_{6} \mathrm{H}_{4}
\end{aligned}
$$

Scheme 15: Oxidation of alcohols and benzylamines using IL-supported-iodobenzene diacetates $\mathbf{5 3}$ and $\mathbf{5 4}$.

The reaction of aryl propiophenones 21 with $\mathbf{5 3}$ or $\mathbf{5 4}$ under acidic conditions underwent 1,2-rearrangement to give methyl-2-arylpropanoates 56 (Scheme 16). On the other hand, Hofmann rearrangement of primary amides $\mathbf{5 7}$ in the presence of $\mathbf{5 3}$ or $\mathbf{5 4}$ under basic conditions gave carbamates 58 in excellent yields and high purities (Scheme 16).

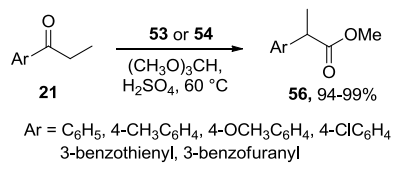

$$
\begin{aligned}
& \mathrm{RCONH}_{2} \underset{\mathrm{KOH}, \mathrm{CH}_{3} \mathrm{OH}}{\stackrel{53}{\mathrm{OH}} \mathbf{2 4}} \mathrm{RNHCO}_{2} \mathrm{CH}_{3} \\
& 57 \quad 0{ }^{\circ} \mathrm{C}-\mathrm{rt} \quad 58,96-99 \% \\
& \mathrm{R}=\mathrm{C}_{6} \mathrm{H}_{5}, 4-\mathrm{CH}_{3} \mathrm{C}_{6} \mathrm{H}_{4}, 4-\mathrm{OCH}_{3} \mathrm{C}_{6} \mathrm{H}_{4}, 4-\mathrm{ClC}_{6} \mathrm{H}_{4} \text {, } \\
& \text { vinyl, adamantanthyl }
\end{aligned}
$$

Scheme 16: 1,2-Rearrangement of propiophenones and Hofmann rearrangement of amides using 53 and $\mathbf{5 4}$. 
Togo group also developed a new procedure for the synthesis of oxazoles $\mathbf{3 5}$ from acetophenones $\mathbf{3 1}$ and acetonitrile using 53 or 54 (Scheme 17). The procedure was quite similar to ionic liquid-supported iodobenzene and mCPBA. ${ }^{77}$ Use of $\mathrm{PhI}(\mathrm{OAc})_{2}$ in place of $\mathbf{5 3}$ or $\mathbf{5 4}$ resulted in comparative yields but the purity of the products were poor due to the release of iodobenzene (co-product), and chromatographic separation was required to get pure compounds. On the other hand, when 53 or 54 were used, the products were isolated in high purity by simple ether extraction.

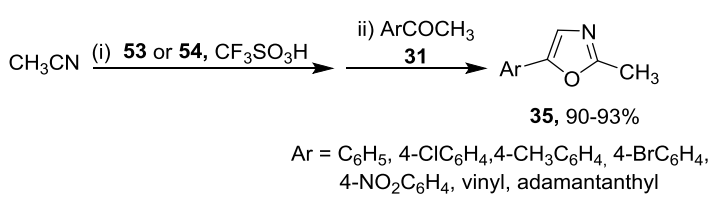

Scheme 17: Synthesis of oxazoles from nitriles and ketones using IL-supported iodobenzene diacetates $\mathbf{5 3}$ and $\mathbf{5 4}$.

\subsubsection{Ionic liquid-supported HTIB or Koser's salt}

Handy and Okello prepared a novel ionic liquid-supported hydroxyl(tosyloxy)iodobenzene (HTIB) or Koser's salt 62 as shown in Scheme 18. ${ }^{85}$ Initially, 4-iodobenzoyl chloride 60 was anchored onto the fructose derived ionic liquid alcohol $\mathbf{5 9}^{86,87}$ by an ester linkage. Oxidation of $\mathbf{6 1}$ with peracetic acid followed by treatment with $p$-TsOH, gave corresponding reagent 62 in good yields.

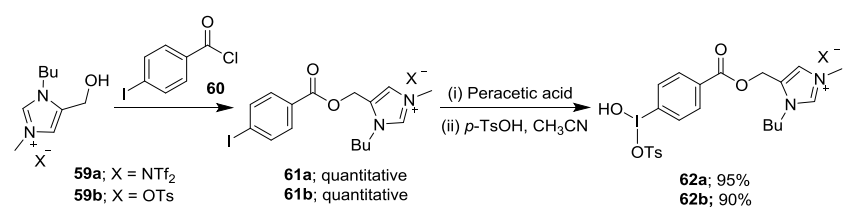

Scheme 18: Synthesis of IL-supported Koser's salt 62.

The synthesized IL-supported Koser's salt was used for the tosyloxyation of ketones (Scheme 19). The reaction of ketones 21 with 62a gave tosyloxyketone $\mathbf{6 3}$ in good yields. However, chromatographic purification was required to separate the product from the by-product 61a due to its high solubility in organic solvents such as acetone, ether, ethyl acetate, and dichloromethane. When $\mathbf{6 2} \mathbf{b}$ in which triflamide ion of 62a was replaced with harder tosylate (-OTs) ion, tosyloxyketones 63 were isolated by simple ether extraction as the by-product $\mathbf{6 1 b}$ was less soluble in ether. It is important to note that $\alpha$-tosylation was faster with $\mathbf{6 3}$ compared to Koser's salt due to the electron withdrawing ester linkage.

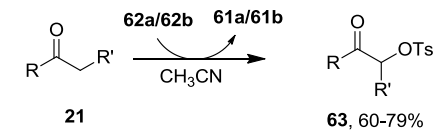

$\mathrm{R}=\mathrm{CH}_{3}, \mathrm{CH}_{3} \mathrm{CH}_{2}, \mathrm{C}_{6} \mathrm{H}_{5}, \mathrm{R}^{\prime}=\mathrm{H}, \mathrm{CH}_{3}, \mathrm{R}-\mathrm{R}^{\prime}=-\left(\mathrm{CH}_{2}\right)_{4^{-}},-\left(\mathrm{CH}_{2}\right)_{3}-$

Scheme 19: Synthesis of $\alpha$-tosyloxy ketones using IL-supported Koser's salt $\mathbf{6 2}$.

Taking into the account that alteration in the anion or cation may lead to the stability of ionic liquid, Zhang group developed a novel pyridinium salt-supported HTIB 69 (Scheme 20). ${ }^{88}$ Reagent 69 was prepared by using modified Zinckes reaction in three steps. $N$-alkylation of pyridine with 1-chloro-2,4-dinitrobenzene $\mathbf{6 5}$ gave $\mathbf{6 6}$, which upon reaction with 4-iodoaniline $\mathbf{6 6}$ followed by anion exchange gave 68. Oxidation of 68 with $m$ CPBA followed by the tosylation yielded pyridinum salt-supported HTIB 69 (Scheme 20). Reagent 69 was found to be relatively more stable than previously reported ionic liquid-supported HTIBs. ${ }^{85}$

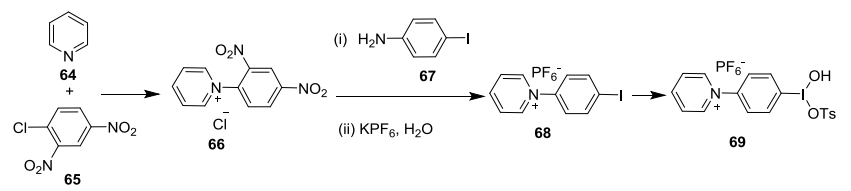

Scheme 20: Synthesis of pyridinium salt-supported HTIB 69.

Tosyloxylation of various ortho-substituted phenolic compounds 70 was explored using 69 (Scheme 21). The reaction of 69 with phenols bearing electron withdrawing groups at ortho positions resulted in desired products $\mathbf{7 1}$ but failed to give desired products from simple phenol and electron rich phenols. Reagent $\mathbf{6 9}$ can be regenerated from by-product $\mathbf{6 8}$ and reused up to 3 cycles without loss in reactivity.

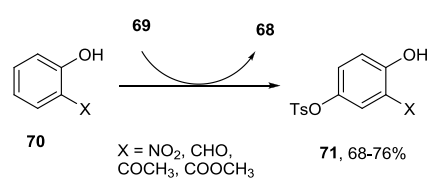

Scheme 21: Tosyloxylation of phenols using 69.

Recently, we have successfully developed a novel imidazolium based ionic liquid-supported hypervalent iodine reagent $\mathbf{7 4}$ and employed it in a 'catch and release' strategy. ${ }^{89}$ Synthesis of $\mathbf{7 4}$ was achieved by mixing a homogeneous solution of ionic liquid-supported sulfonic acid 73 in $\mathrm{CH}_{3} \mathrm{CN}$ with a hot solution of iodobenzene diacetate (IBD) and keeping it at room temperature for one week (Scheme 22).

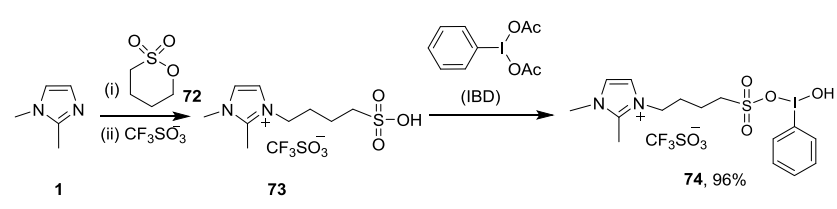

Scheme 22: Synthesis of IL-supported hypervalent iodine reagent 74 .

After successfully synthesizing $\mathbf{7 4}$, it was used to develop a chromatographic free protocol for the synthesis of $\alpha$-substituted acetophenones $\mathbf{7 6}$ by first capturing acetophenones $\mathbf{7 5}$ on ionic liquid followed by nucleophilic release with $\mathrm{KSCN}, \mathrm{NaN}_{3}$ and $\mathrm{PhSO}_{2} \mathrm{Na}$ (Scheme 23). ${ }^{89}$ Small library of $\alpha$-thiocynato- $\beta$-ketones $\mathbf{7 6 a}$, $\alpha$-azido- $\beta$-ketones 76b and $\beta$-ketosulfones 76c have been 
synthesized in good to excellent yields (46-92\%) using this strategy. Superior loading capacity and chromatography-free synthesis are inherent advantages of this process.

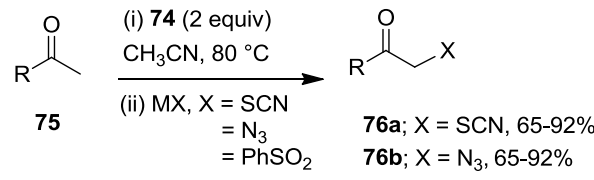

$$
\begin{aligned}
& \text { 76c; } \mathrm{X}=\mathrm{PhSO}_{2}, 46-68 \%
\end{aligned}
$$

$$
\mathrm{R}=4-\mathrm{ClC}_{6} \mathrm{H}_{4}, 3-\mathrm{ClC}_{6} \mathrm{H}_{4}, 4-\mathrm{BrC}_{6} \mathrm{H}_{4}, 4-\mathrm{CH}_{3} \mathrm{C}_{6} \mathrm{H}_{4} \text {, }
$$

4- $-\mathrm{OCH}_{3} \mathrm{C}_{6} \mathrm{H}_{4}, 4-\mathrm{NO}_{2} \mathrm{C}_{6} \mathrm{H}_{4}, \mathrm{C}_{4} \mathrm{H}_{3} \mathrm{~S}$, 2-napthyl

Scheme 23: Synthesis of $\alpha$-substituted ketones using IL-supported hypervalent iodine reagent 74.

\subsubsection{Ionic liquid-supported diaryliodonium salts}

Diaryliodonium salts serves as proficient and potent electrophilic arylating source for the carbon-carbon and carbon-heteroatom bond formation reactions. ${ }^{90}$ To deal with the purification, isolation, and loading problems of diaryliodonium salts, recently we have developed new ionic liquid-supported diaryliodonium salts. ${ }^{91}$ Electron-rich aryl groups, like alkoxyphenyl and thiophene, have been grafted on ionic liquids for the facile synthesis of ionic liquid-supported diaryliodonium salts as shown in the Scheme 24. These imidazolium-supported aryls $\mathbf{7 9}$ and $\mathbf{8 0}$ further reacted with hydroxyl(tosyloxy)iodoarene (HTIA) or (diacetoxyiodo)arenes to give corresponding ionic liquid-supported diaryliodonium salts $\mathbf{8 1}$ and 82. They were isolated in pure form by simple washing with organic solvents like chloroform and tetrahydrofuran, without requiring chromatographic purification; moreover, these salts are quite stable and have not shown any sign of decomposition or loss of reactivity even after one month of storing at $5{ }^{\circ} \mathrm{C}$.

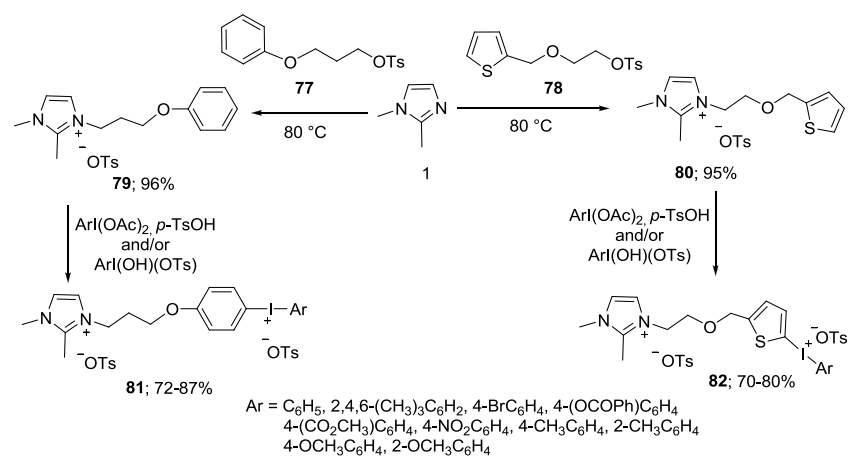

Scheme 24: Synthesis of IL-supported diaryliodonium salts.

Metal-free electrophilic phenylation of phenols $\mathbf{8 3}$ and carboxylic acids 85 was performed using $\mathbf{8 1}$ or $\mathbf{8 2}$ to give phenyl ether $\mathbf{8 4}$ and carboxylic esters $\mathbf{8 6}$, respectively. in good yields (Scheme 25). Products 84 and $\mathbf{8 6}$ were isolated simply by evaloparting the reaction solvent followed by extraction with a hexane/ethyl acetate mixture. This left behind the by-product supported on the ionic liquid, which can potentially be reused as a supported reagent in many other organic transformations. Better yields for phenylation were obtained using $\mathbf{8 1}$ as compared with $\mathbf{8 2}$.

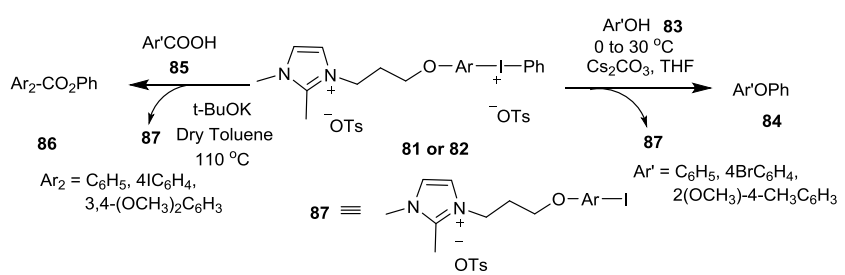

Scheme 25: Electrophilic phenylation of phenols and carboxylic acids using $\mathbf{8 1}$ or $\mathbf{8 2}$.

\subsection{Ionic liquid-supported TEMPO}

Chemoselective oxidation of alcohols to corresponding carbonyl compounds is an important process in synthetic organic chemistry. ${ }^{92}$ TEMPO is widely used co-catalyst along with terminal oxidant for this process due to its non-metallic nature. ${ }^{93}$ Although the amount of TEMPO required for the oxidation process is quite less (1-5 mol \%), in order to make the whole process cost effective, there is a need to recycle and reuse the co-catalyst. To address the problems associated with recyclability and reusability, TEMPO has been grafted onto various supports. ${ }^{94}$

Wu et al. synthesized ionic liquid-supported TEMPO 89 from 4-hydroxy-TEMPO $\mathbf{8 8}$ in a two-step process. ${ }^{95}$ Coupling of $\mathbf{8 8}$ with chloroacetyl chloride or chloroacetic acid followed by quaternization with 1-methylimidazole 14 and anion exchange with $\mathrm{KPF}_{6}$ or $\mathrm{NaBF}_{4}$ gave $\mathbf{8 9}$ in good yields (Scheme 26). Qian et al. also reported the synthesis of various ionic liquid-supported TEMPO 89b, 98a and $\mathbf{9 8 b}$ by grafting 88 onto an imidazolium ion as shown in Scheme $26 .^{81}$ Oxidation of alcohols $\mathbf{7}$ using 89 along with terminal oxidant sodium hypochlorite $\left(\mathrm{NaClO}_{4}\right)$ in a biphasic mixture of $[\mathrm{bmim}]\left[\mathrm{PF}_{6}\right]$-water gave excellent yield $(86-96 \%)$ of carbonyl compounds $\mathbf{8}$ (Scheme 27, method A). ${ }^{95}$ Comparable catalytic activity was observed for 89 a to that of TEMPO and efficient recyclability and reusability of $\mathbf{8 9}$ were inherent advantages of this process.

Tong group developed a heterogeneous method for the oxidation of alcohols $\mathbf{7}$ to carbonyl compounds $\mathbf{8}$, by impregnating 89b and $\mathrm{CuCl}$ on to various silica supports including $\mathrm{SiO}_{2}, \mathrm{MCM}-41$ and SBA-15. ${ }^{96}$ The heterogeneous catalyst has shown superior catalytic activity compared to ionic liquid-TEMPO/CuCl system (Scheme 27, method B). Fall et al. reported a new ionic liquid-supported TEMPO 92 via a click reaction as shown in Scheme 26. ${ }^{97}$ Reaction of $\mathbf{8 8}$ with propargyl bromide $\mathbf{9 0}$ in DMF followed by click reaction with azido functionalized ionic liquid $\mathbf{9 1}$ in the presence of $\mathrm{CuSO}_{4}$ /sodium ascorbate gave 92 in moderate yield (59\%). The catalytic activity of $\mathbf{9 2}$ for the oxidation of alcohols 7 was evaluated in various ionic liquids such as $[\mathrm{hmim}]\left[\mathrm{BF}_{4}\right], \quad[\mathrm{hmim}][\mathrm{Cl}], \quad[\mathrm{bmim}]\left[\mathrm{BF}_{4}\right] \&$ [omim $][\mathrm{Cl}]$. Among all these ionic liquids, $[\mathrm{hmim}]\left[\mathrm{BF}_{4}\right]$ proved to be the solvent of choice for this reaction (Scheme 27, method C).

Zhdankin and group have synthesized a bifunctional hybrid-type ionic liquid-supported TEMPO 96 (Scheme 


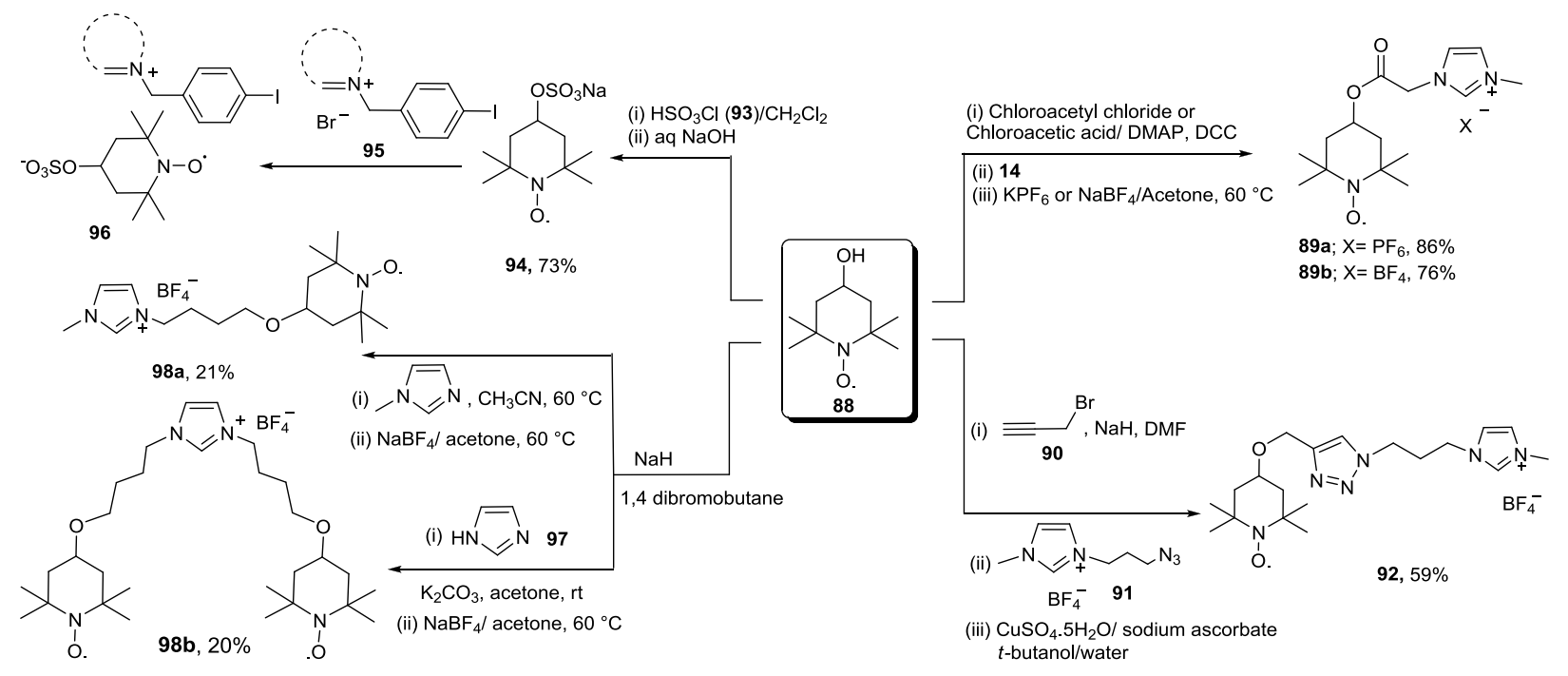

Scheme 26: Synthesis of various IL-supported TEMPO.

26). ${ }^{98}$ For the synthesis of $\mathbf{9 6}$, iodobenzene was integrated to the cationic part of ionic liquid by quaternization of 1-methylimidazole or pyridine with 1-(bromomethyl)-4-iodobenzene to generate ionic liquid 95. TEMPO was introduced as the anion part of ionic liquid by anion metathesis of 95 with $\mathrm{Na}$ [TEMPO-OSO 3$] 94$.

Qian et al. also studied catalytic activity of $\mathbf{8 9 b}$ and 98 in the oxidation of alcohols 7 using a stochiometric amount of terminal oxidants like peracetic acid, IBD, [dibmim] $\left[\mathrm{BF}_{4}\right]$, sodium hypochlorite, and iodine (Scheme 27, method D). Superior catalytic activity was observed for $\mathbf{9 8 b}$ due to its higher loading capacity, where as $\mathbf{8 9 b}$ and 98a showed similar catalytic activity to TEMPO. Of the various terminal oxidants that were screened, [dibmim] $\left[\mathrm{BF}_{4}\right]$ gave the best result and this may be attributed to its complete solubility in water.

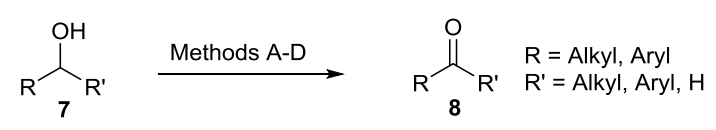

Method A: 89a (1 mol \%), $\mathrm{NaOCl}(1.2$ equiv), $\mathrm{KBr}(10 \mathrm{~mol} \%), \mathrm{pH}=8.6$, [bmim] $\left[\mathrm{PF}_{6}\right], \mathrm{H}_{2} \mathrm{O}, 0^{\circ} \mathrm{C}, 86-96 \%$

Method B: $89 \mathrm{a} / \mathrm{CuCl}_{2} / \mathrm{SiO}_{2}, \mathrm{O}_{2}, n$-Octane, $70{ }^{\circ} \mathrm{C}$

Method C: 92 (10 mol \%), IBD (1.1 equiv), [hmim] [BF 4 ], $\mathrm{H}_{2} \mathrm{O}, 30^{\circ} \mathrm{C}, 86-99 \%$ Method D: $\mathbf{8 9 b}, \mathbf{9 8 a}$, or $\mathbf{9 8 b}\left(5 \mathrm{~mol} \%\right.$ ), [dibmim] $\left[\mathrm{BF}_{4}\right], \mathrm{H}_{2} \mathrm{O}, 30^{\circ} \mathrm{C}, 78-99 \%$

Scheme 27: Oxidation of alcohols using IL-supported TEMPO.

Zhdankin et al. has further studied oxidation of alcohols 7 to hydrazone derivatives 99 using catalytic amount of 96 along with stoichiometric amount of peracetic acid (Scheme 28). ${ }^{98}$ Remarkable rate-enhancing effect has been noticed when 1,1,1,3,3,3-hexafluoroisopropanol (HFIP) was used as co-solvent in this oxidation process. Due to the presence of both functionalities (iodobenzene and TEMPO) on the same moiety (96), oxidation process is believed to be intramolecular rather than intermolecular. Superior catalytic activities, no apparent loss in catalytic activity even after five cycles, and easy separation of products from the

reaction mixture are advantages of this process.

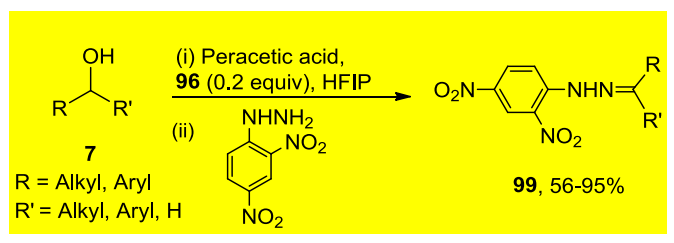

Scheme 28: Conversion of alcohols 7 to hydrazones 99 using IL-supported TEMPO 96.

In all these cases, the biphasic system offered easy isolation of products from the reaction mixture, and ionic liquid-supported TEMPO could be reused several times without much loss of catalytic activity. These systems offer clean, convenient and environmentally benign method for the selective oxidation of alcohols.

\subsection{Ionic liquid-supported nitrating reagent}

In an interesting study, Zolfigol et al. reported a novel bifunctional ionic liquid $\mathbf{1 0 1}$ having sulfonic acid and nitrate ion. ${ }^{50}$ Synthesis of $\mathbf{1 0 1}$, was achieved by the reaction of 1-methylimidazole $\mathbf{1 4}$ with chlorosulfonic acid to give $\mathbf{1 0 0}$ followed by addition of nitric acid to $\mathbf{1 0 0}$ under solvent free conditions (Scheme 29). Nitration of aromatic compounds was studied using $\mathbf{1 0 1}$ and a wide range of aromatic compounds 105 were nitrated under mild conditions in good to excellent yields. Successful nitration of aniline and a significant decrease in the yield on employing free radicals scavengers (iodine, butylated hydroxytoluene) are clear evidence that nitration occurs due to the generation of $\mathrm{NO}_{2}$ radical rather than $\mathrm{NO}_{2}{ }^{+}$ion. Moreover, $21 \%$ weight loss on heating the reagent 101 from 60 to $160{ }^{\circ} \mathrm{C}$ and formation of $\mathrm{Cu}\left(\mathrm{NO}_{3}\right)_{2}$ by the reaction of copper metal during the heating process are some other evidences that support that this nitration process proceeds via $\mathrm{NO}_{2}$ radical rather than $\mathrm{NO}_{2}{ }^{+}$. The reagent 101 can be regenerated and reused efficiently (Scheme 29). 


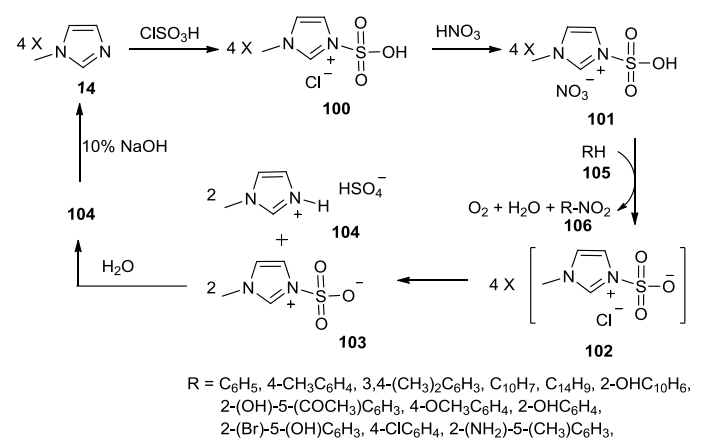

Scheme 29: Synthesis of IL-supported reagent 101 and aromatic nitration using $\mathbf{1 0 1}$.

\subsection{Ionic liquid-supported organotin reagents}

Legoupy and co-workers synthesized ionic liquid-supported organotin reagents 108-111. ${ }^{99-102}$ Substitution reaction of $\mathbf{1 0 6}$ with tributyltin lithium produced $\mathbf{1 0 7}$, which upon reaction with alkyl iodide gave desired organotin reagent 108 . Reaction of $\mathbf{1 0 8}$ with hydrochloric acid in ether produced ionic liquid-supported chlorostannane $\mathbf{1 0 9}$ that on further reaction with alkyl/arylmagnesium bromides resulted in liquid-supported organotin reagents 111a-e (Scheme 30). Different functional groups, such as vinyl, allyl, methoxy, and fluoro, were well tolerated under these conditions.

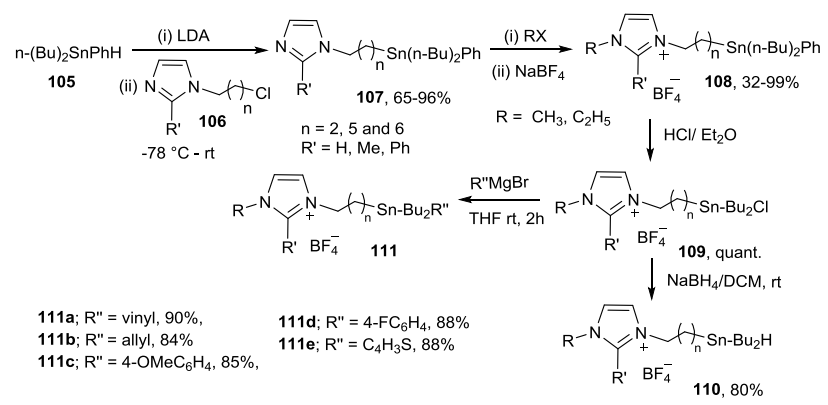

Scheme 30: Synthesis of IL-supported organotin reagents.

The investigators further studied Stille cross coupling of aryl halides 112 using 108-111. Dibutyldiphenylstannane was obtained by the reaction of iodobenzene with $\mathbf{1 0 8}$ in the presence of $\mathrm{Pd}\left(\mathrm{PPh}_{3}\right)$ and $\mathrm{CuI}$ instead of expected biphenyl 114. After optimizing the reaction conditions, it was found that use of $\mathrm{Pd}_{2}(\mathrm{dba})_{3} . \mathrm{CHCl}_{3}$ gave the desired biphenyl 114 in high yields even in the absence of CuI. ${ }^{99}$ Legoupy et al. further studied the use of the $\mathbf{1 0 8}$ in other Stille cross coupling reactions using various aryl halides 112 including 4-methoxyiodobenzenes, 3-bromo/iodopyridine and 2-iodothiophene. ${ }^{101,102}$ In most of the cases, along with desired product $113(\mathrm{Ar}-\mathrm{Ph})$, unwanted homocoupling products 114 and 115 ( $\mathrm{Ph}-\mathrm{Ph}, \mathrm{Ar}-\mathrm{Ar})$ were also formed as shown in Scheme 31. The procedure was further extended to various ionic liquid-supported organotin reagents 111a-e. Surprisingly, there was no homocoupling products formation observed when 111a-e were reacted with aryl bromides (Scheme 31). ${ }^{101}$ The reagents could be easily regenerated from co-product $\mathbf{1 0 9}$ by the addition of PhLi in THF.

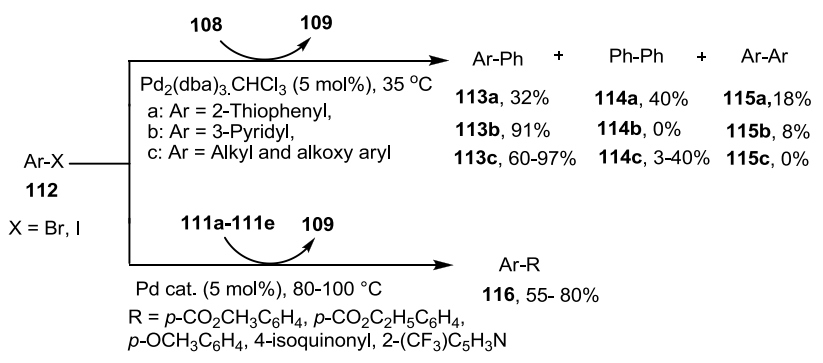

Scheme 31: Stille cross coupling reaction using IL-supported tin reagent.

Legoupy and co-workers also reported the reduction of alkyl and aryl halides using ionic liquid-supported organotin reagents 109 and $\mathbf{1 1 0} .^{100}$ Reaction of $\mathbf{1 0 9}$ with $\mathrm{NaBH}_{4}$ resulted in the formation of ionic liquid-supported stannane 110 in $80 \%$ yield (Scheme 30). A variety of alkyl and aryl halides 117 were reduced to the corresponding hydrocarbons 118 in high to excellent yields using 109 in the presence of AIBN and $\mathrm{NaBH}_{4}$ (Scheme 32, method A). AIBN was believed to enhance the formation of organotin radical, thus promoting the reduction of alkyl and aryl halides. Similarly, alkyl and aryl halides were reduced to $\mathbf{1 1 8}$ using $\mathbf{1 1 0}$ in the presence of AIBN (Scheme 32, method B). Reagent 110 was shown to have excellent tolerance to a variety of functional groups including keto and ester. The counter anion $\left(\mathrm{I}^{-} / \mathrm{BF}_{4}^{-}\right)$ of the reagent also played a key role in the yield of the reaction as reagent $\mathbf{1 1 0}$ and $\mathbf{1 1 0}$ with counter anion $\mathrm{I}^{-}$ showed enhanced reactivity.

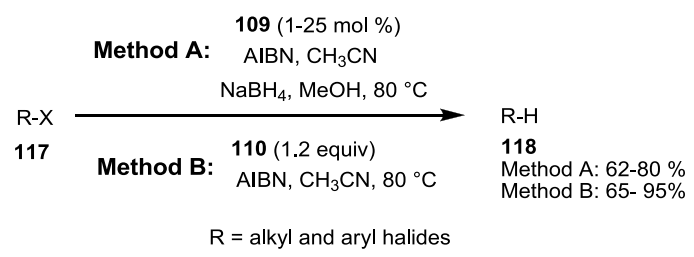

Scheme 32: Reduction of alkyl/aryl halides using IL-supported organotin reagents $\mathbf{1 0 9}$ and $\mathbf{1 1 0}$.

\subsection{Ionic liquid-supported phosphine derivatives}

\subsubsection{Ionic liquid-supported triphenylphosphine}

Triphenylphosphine $\left(\mathrm{Ph}_{3} \mathrm{P}\right)$ is widely used as a ligand in transition metal catalyzed coupling reactions. Removal of $\mathrm{Ph}_{3} \mathrm{P}$ and $\mathrm{Ph}_{3} \mathrm{PO}$ (co-product in some reactions) from the reaction mixture is very troublesome and requires repetitive column chromatography. Keeping this in view, Togo et al. synthesized ionic liquid-supported triphenylphosphines 122. ${ }^{103}$ The reagents $\mathbf{1 2 2 a}$ and $\mathbf{1 2 2 b}$ were prepared from substituted aryl bromides $\mathbf{1 1 9}$ as shown in Scheme 33. In situ generation of Grignard reagent from 119, followed by reaction with $\mathrm{Ph}_{2} \mathrm{PCl}$ and oxidation yielded phosphine oxide 120, which was anchored onto an ionic liquid by quaternization of tertiary amines to give 121. Reduction of 121 using $\mathrm{LiAlH}_{4}$ followed by acidification with $\mathrm{HBr}$ gave reagents 122a and 122b in good yields (Scheme 33). 


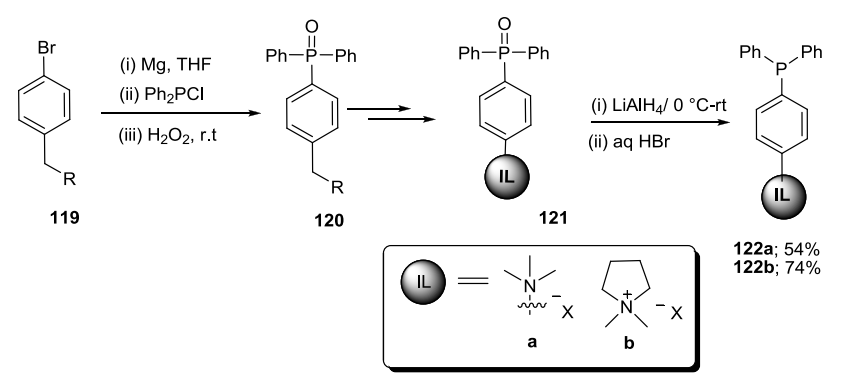

Scheme 33: Synthesis of IL-supported triphenylphosphine.

Reagent 122a, 122b and $\mathrm{Ph}_{3} \mathrm{P}$ were screened independently for the halogenation of alcohols $\mathbf{1 2 3}$ to corresponding halides $\mathbf{1 2 4}$ (Scheme 34). ${ }^{103,} 104$ When $\mathbf{1 2 2}$ was employed as a reagent, products were isolated in good yields with high purity (>70\%) by simple filtration and by-products 121a and 121b were recovered in over $90 \%$ yield. The recovered $\mathbf{1 2 1}$ were again reduced to $\mathbf{1 2 2}$ and reused. On the other hand, when $\mathrm{Ph}_{3} \mathrm{P}$ was employed, the purity of the products $\mathbf{1 2 4}$ was quite less $(<45 \%)$ and they were purified by column chromatography.

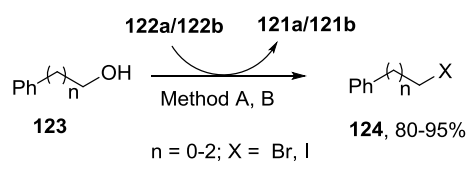

Method $\mathrm{A}: \mathrm{CBr}_{4}$ (1.1 equiv) 122a (1.2 equiv) or $122 \mathrm{~b}$ (1.5 equiv), solvent, $40^{\circ} \mathrm{C}-60^{\circ} \mathrm{C}$ Method $B: I_{2}$ ( 1.5 equiv), 122a (1.2 equiv) or $122 b$ ( 1.5 equiv), imidazole (1.5 equiv), $\mathrm{KI}\left(1.5\right.$ equiv), $40^{\circ} \mathrm{C}-60^{\circ} \mathrm{C}$

Scheme 34: Halogenation of alcohols using 122.

Togo group further explored application of $\mathbf{1 2 2}$ in Mitsunobu and amide bond formation reactions (Scheme 35). Carboxylic acids $\mathbf{1 2 5}$ were converted to corresponding esters $\mathbf{1 2 6}$ by reaction with alcohols $\mathbf{1 2 6}$ in the presence of 122 in excellent yields, and the ionic liquid-supported phosphine oxide 121 was recovered. Similarly, amides $\mathbf{1 2 9}$ were obtained in excellent yields (83-99\%) and high purity by the reaction of $\mathbf{1 2 5}$ with amines $\mathbf{1 2 8}$ in the presence of $122 b$.

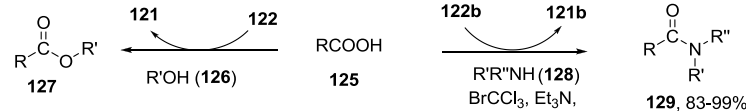

$$
\begin{aligned}
& \mathrm{R}=4-\mathrm{OCH}_{3} \mathrm{C}_{6} \mathrm{H}_{4}\left(\mathrm{CH}_{2}\right)_{2} \quad \mathrm{R}=\mathrm{C}_{6} \mathrm{H}_{5}, 4-\mathrm{NO}_{2} \mathrm{C}_{6} \mathrm{H}_{4}, 4-\mathrm{ClC}_{6} \mathrm{H}_{4}, 4-\mathrm{BrC}_{6} \mathrm{H}_{4}, 4-\mathrm{IC}_{6} \mathrm{H}_{4}, 4-\mathrm{FC}_{6} \mathrm{H}_{4} \text {, } \\
& \mathrm{R}^{\prime}=\mathrm{C}_{6} \mathrm{H}_{5}\left(\mathrm{CH}_{2}\right)_{2} \quad 4-\mathrm{CH}_{3} \mathrm{C}_{6} \mathrm{H}_{4}, 4-\mathrm{OCH}_{3} \mathrm{C}_{6} \mathrm{H}_{4}, 4-\mathrm{N}_{2}\left(\mathrm{CH}_{3}\right)_{2} \mathrm{C}_{6} \mathrm{H}_{4}, \mathrm{C}_{6} \mathrm{H}_{5} \mathrm{CHCH}_{2}, 4-\mathrm{ClC}_{6} \mathrm{H}_{4} \mathrm{CHCH}_{2}
\end{aligned}
$$

Scheme 35: Ester and amide bond formation using 122.

The success of these reactions encouraged Togo group to examine $\mathbf{1 2 2}$ as ligands in the Mizoroki-Heck and Sonogashira coupling reaction. ${ }^{103}$ A comparative study performed for the reuse of the catalyst for these coupling reactions in the absence and presence of $\mathbf{1 2 2}$ showed that when 122 was employed not only the rate of the reactions were dramatically accelerated but $\mathrm{Pd}(\mathrm{OAc})_{2}$ and $\mathrm{CuI}$ could be recovered and reused several times (Scheme 36). The coupling products $\mathbf{1 3 2}$ and $\mathbf{1 3 4}$ were isolated in pure form by simple extraction with appropriate organic solvents.

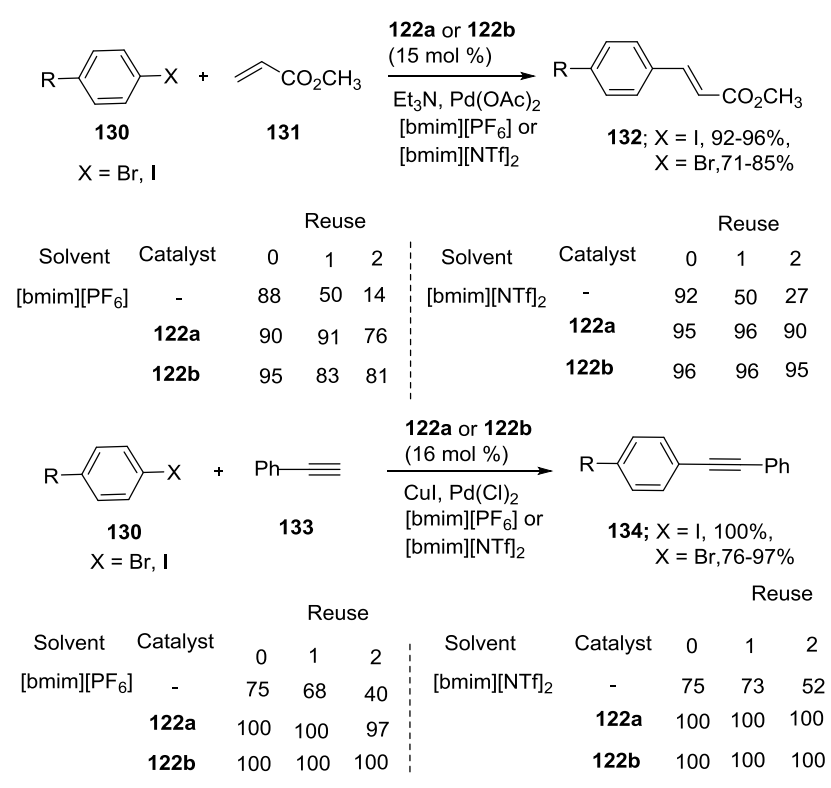

Scheme 36: Mizoroki-Heck and Sonogashira coupling reactions in the absence and presence of $\mathbf{1 2 2}$.

Togo group also developed an efficient procedure for Aza-Morita-Baylis-Hillman reaction using $\mathbf{1 2 2}$ as a reusable catalyst. ${ }^{104}$ Various $N$-benzylidinecarbamate imines and $N$-tosylarylimines $\mathbf{1 3 5}$ were reacted alkenes $\mathbf{1 3 1}$ in the presence of 122a and 122b to give corresponding Baylis-Hillman adducts 136 in good to excellent (50-99\%) yields and high purity (Scheme 37). Among various solvents that were screened, best yield of $\mathbf{1 3 6}$ was obtained in $\mathrm{CH}_{2} \mathrm{Cl}_{2}$. Further increase in the yield and purity was

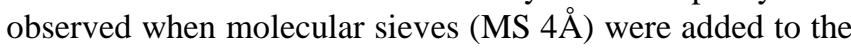
reaction mixture. The increase in the yield of products is attributed to the removal of moisture from $\mathbf{1 2 2}$ by MS $4 \AA$.

$$
\begin{aligned}
& \overbrace{135}^{N_{H}^{-X}}+\int_{131}^{E W G} \stackrel{\text { Method A-C }}{\longrightarrow} \\
& \begin{array}{rr}
131 & 136,50-99 \%(\text { Method } \mathrm{A}) \\
& 62-98 \%(\text { Method } \mathrm{B})
\end{array} \\
& \mathrm{R}=\mathrm{C}_{6} \mathrm{H}_{5}, 4-\mathrm{ClC}_{6} \mathrm{H}_{4}, 2-\mathrm{ClC}_{6} \mathrm{H}_{4}, 4-\mathrm{BrC}_{6} \mathrm{H}_{4}, \quad 62-98 \% \text { (Method } \mathrm{B} \text { ) } \\
& \begin{array}{l}
\text { 4- } \mathrm{FC}_{6} \mathrm{H}_{4}, 4-\mathrm{NO}_{2} \mathrm{C}_{6} \mathrm{H}_{4}, 4-\mathrm{CH}_{3} \mathrm{C}_{6} \mathrm{H}_{4} \text {, } \\
\text { Napthyl, 2-thienyl, 3-pyridyl }
\end{array} \\
& X=T s, C b z \text {, } \\
& \mathrm{EWG}=\mathrm{CN}, \mathrm{COOCH}_{3} \\
& \text { Method A: } 122 \mathrm{a} \text { or } 122 \mathrm{~b} \text { ( } 0.5 \text { equiv), DCM, MS } 4 \mathrm{~A}^{\circ} \text {, rt } \\
& \mathrm{COCH}_{3}, \mathrm{COC}_{2} \mathrm{H}_{5} \\
& \text { Method B: 180ab' (0.3 equiv), MeOH (2 equiv), } \\
& \text { Method C: } 180 \mathrm{ca} \text { ( } 0.2 \text { equiv), }
\end{aligned}
$$

\section{Scheme 37: Aza-Morita-Baylis-Hillman reaction using 122.}

\subsubsection{Ionic liquid-supported phosphonium salts}

liquid-supported phosphonium salts 137aa'-ac' and $137 \mathbf{b a}^{\prime}-\mathbf{b c}^{\prime}$ were synthesized by the alkylation of 122a and 122b with $p$-methylbenzyl bromide, ethyl bromoacetate and $n$-butyl bromide as shown in Scheme 38. ${ }^{105}$

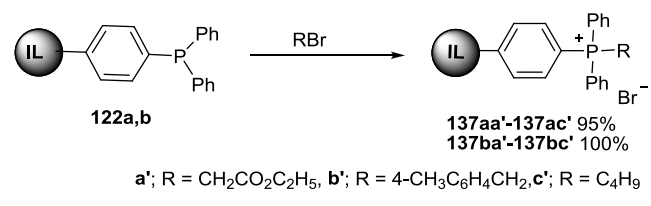

Scheme 38: Synthesis of IL-supported phosphonium salts. 
Ionic liquid-supported phosphonium salts $\mathbf{1 3 7}$ were used in Wittig reaction as alkyl source. Aldehydes 47 were converted to corresponding alkenes $\mathbf{1 3 8}$ in high yields and excellent purities by reacting with 137 (Scheme 39). ${ }^{105}$ Trans-isomer was obtained as a major product in case of 138a and $\mathbf{1 3 8 b}$ whereas cis-isomer was a major product in case of $138 c$.

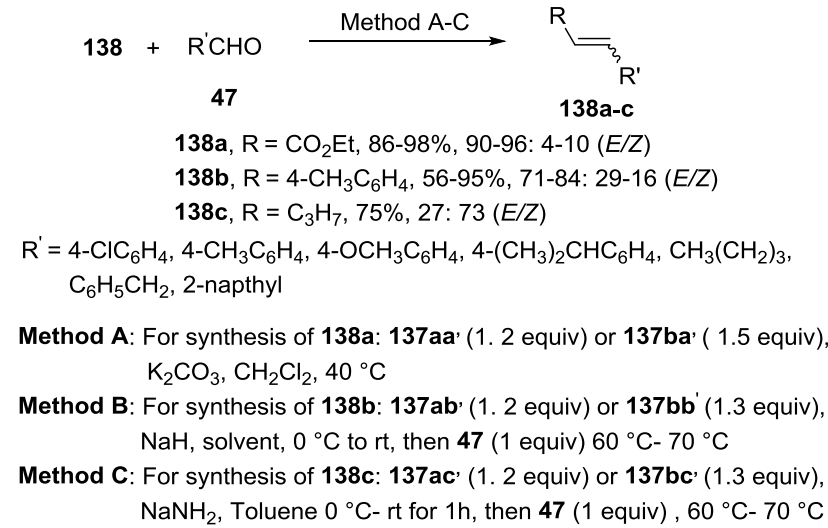

Method A: For synthesis of 138a: 137aa' (1. 2 equiv) or 137ba' ( 1.5 equiv), $\mathrm{K}_{2} \mathrm{CO}_{3}, \mathrm{CH}_{2} \mathrm{Cl}_{2}, 40^{\circ} \mathrm{C}$

Method B: For synthesis of 138b: 137ab' (1. 2 equiv) or 137bb' (1.3 equiv), $\mathrm{NaH}$, solvent, $0{ }^{\circ} \mathrm{C}$ to $\mathrm{rt}$, then 47 ( 1 equiv) $60^{\circ} \mathrm{C}-70{ }^{\circ} \mathrm{C}$

Method C: For synthesis of 138c: 137ac' (1. 2 equiv) or 137bc' (1.3 equiv), $\mathrm{NaNH}_{2}$, Toluene $0{ }^{\circ} \mathrm{C}$ - rt for $1 \mathrm{~h}$, then 47 (1 equiv) , $60{ }^{\circ} \mathrm{C}-70{ }^{\circ} \mathrm{C}$

Scheme 39: Wittig reaction using 137.

\subsubsection{Diphenylphosphinite-functionalized ionic liquids}

Iranpoor and co-workers have described the synthesis of diphenylphosphinite-functionalized ionic liquids $\left(\mathrm{IL}-\mathrm{OPPh}_{2}\right)$ 140 by the reaction of chlorodiphenylphosphine $\left(\mathrm{PPh}_{2} \mathrm{Cl}\right)$ with ionic liquid alcohol $\mathbf{1 3 9}$ in the presence of $\mathrm{Et}_{3} \mathrm{~N}$ (Scheme 40). ${ }^{106}$ Dehalogenation and homocoupling reactions of aryl halides 130 were carried out using 140 both as a reagent and reaction medium (Scheme 40). ${ }^{107,} 108$ The outcome of the reaction relied on the reactants and the bases employed in the reaction. For example, aryl halide 130, in the presence of reagent $140, \mathrm{PdCl}_{2}$ and $\mathrm{Et}_{3} \mathrm{~N}$ resulted in homocoupled product 141. On the contrary, replacement of $\mathrm{Et}_{3} \mathrm{~N}$ with sodium isopropoxide $\left(\mathrm{NaOPr}^{\mathrm{i}}\right)$ resulted in the dehalogenation of aryl halides to give 142. The method proved to be tolerant to various functional groups, such as nitro, keto, and nitrile.

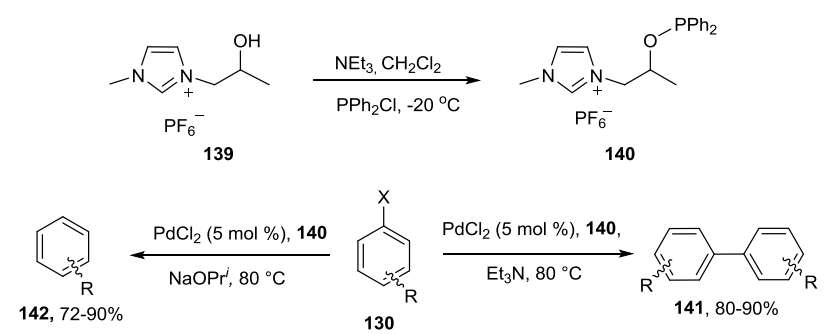

Scheme 40: Synthesis of IL-OPPh 2 and its application in homocoupling and dehalogenation reaction of aryl halides.

Later, 140 was also used as reusable and recyclable ligand in Heck reactions and silylation of aryl halides (Scheme 41). ${ }^{109}$ Aryl halides 130 in the presence of $140, \mathrm{PdCl}_{2}$, and $\mathrm{Et}_{3} \mathrm{~N}$ reacted with styrene or $n$-butyl acrylate to give corresponding Heck coupled products $\mathbf{1 4 3}$ in good to excellent yields (59-97\%). Interestingly, less reactive aryl chlorides also underwent Heck coupling reaction under given reaction conditions. On the other hand, the reaction of aryl halides with triethylsilanes in the presence of $\mathrm{Cs}_{2} \mathrm{CO}_{3}$ gave arylsilanes 144. Surprisingly, in the absence of the base same system resulted dehalogenated products $\mathbf{1 4 2}$.

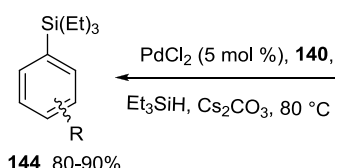

$144,80-90 \%$

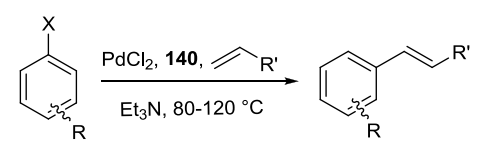

$1301143 ; 59-97 \%$ $\mathrm{R}^{\prime}=\mathrm{C}_{6} \mathrm{H}_{5}, \mathrm{CO}_{2} n-\mathrm{Bu}$
$\mathrm{R}=\mathrm{CH}_{3}, \mathrm{OCH}_{3}, \mathrm{CN}, \mathrm{COCH}_{3}, \mathrm{NO}_{2}, \mathrm{Cl}$

Scheme 41: Heck reaction and silylation of aryl halides using IL-OPPh .

Valizadeh et al. has reported an elegant microwave-assisted synthesis of coumarins $\mathbf{1 4 6}$ from phenols and dialkyl but-2-ynedioate using diphenylphosphinite-functionalized ionic liquid 140 (Scheme 42). ${ }^{110}$ Coumarins were obtained in good yields (65-80\%), and the reagent 140 could be reused at least three times without apparent loss in its activity.

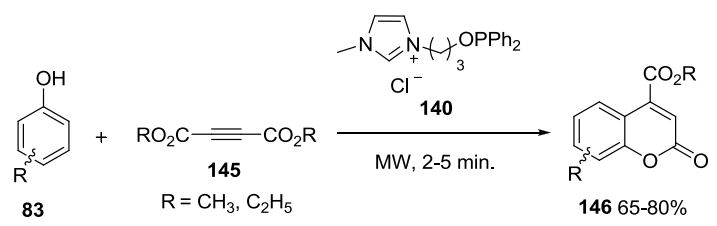

Scheme 42: Microwave-assisted synthesis of coumarins using IL-OPPh$h_{2}$.

Iranpoor and co-workers reported bromination of alcohols, trimethylsilyl and THP-ethers $\mathbf{1 4 7}$ by bromine in the presence of $\mathbf{1 4 0}$ (Scheme 43). ${ }^{106}$ Although the procedure was applicable to all alcohols, trimethylsilyl and THP-ethers, the reagent is highly selective for primary alcohols in the presence secondary alcohols and similarly for primary and secondary alcohols over trimethylsilyl and THP-ethers. The study was further extended to the synthesis of thiocyantes and isothiocyanates by reacting alcohols and their derivatives using IL-OPPh$(\mathrm{SCN})$ which is prepared by the reaction of 140 with bromine followed by the reaction of KSCN. It is worth to emphasize that primary alcohol selectively gave thiocyanates (148a) while tertiary alcohols yielded isothiocyanates (148b). A mixture of thiocyanates and isothiocyanates was obtained from secondary alcohols. ${ }^{106}$ The products were isolated by simple extraction with diethyl ether.

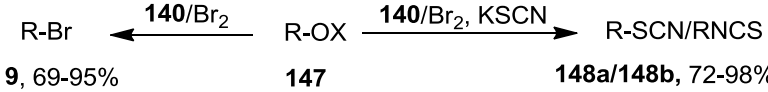

$$
\begin{aligned}
& \mathrm{X}=\mathrm{H}, \mathrm{SiMe}_{3} \text {, THP } \\
& \mathrm{R}=\mathrm{PhCH}_{2},(\mathrm{Ph})_{2} \mathrm{CH}, p-\mathrm{PhC}_{6} \mathrm{H}_{4} \mathrm{C}\left(\mathrm{CH}_{3}\right)_{2}, \mathrm{CH}_{3}\left(\mathrm{CH}_{2}\right)_{6} \mathrm{CH}_{2} \text {, } \\
& \mathrm{CH}_{3} \mathrm{CH}_{2} \mathrm{CH}\left(\mathrm{CH}_{3}\right), 4-\mathrm{CH}_{3} \mathrm{OC}_{6} \mathrm{H}_{4} \mathrm{CH}_{2}, 4-\mathrm{NO}_{2} \mathrm{C}_{6} \mathrm{H}_{4} \mathrm{CH}_{2} \text {, }
\end{aligned}
$$

Scheme 43: Bromination and thiocyanation using 140.

\subsection{Ionic liquid-supported sulfonyl chloride}

Qiao group synthesized an acidic ionic liquid, 1-4[(chlorosulfonyl)butyl]-3-methylimidazolium 
chlorosulfate [cbmim] $\left[\mathrm{SO}_{3} \mathrm{Cl}\right] \mathbf{1 5 0}$ from [sbmim] $\left[\mathrm{HSO}_{4}\right]$ 149 by reacting with $\mathrm{SOCl}_{2}$ (Scheme 44). ${ }^{111}$ Compound 150 features acidic sites on both the anion and cation part of ionic liquid. Dehydration of aldoximes $\mathbf{1 5 1}$ was performed to give nitriles 33 using both 149 and $\mathbf{1 5 0}$ as a catalyst. The reagent 150 was found to be more efficient than 149, and nitriles were obtained in 93-95\% yield using 150 (Scheme 44). Moreover, self-induced phase separation of the reaction mixture after completion of the reaction provided simple and effortless isolation of the products from the reaction mixture. ${ }^{111}$ Recovered 149 was converted to $\mathbf{1 5 0}$ on reacting with $\mathrm{SOCl}_{2}$.

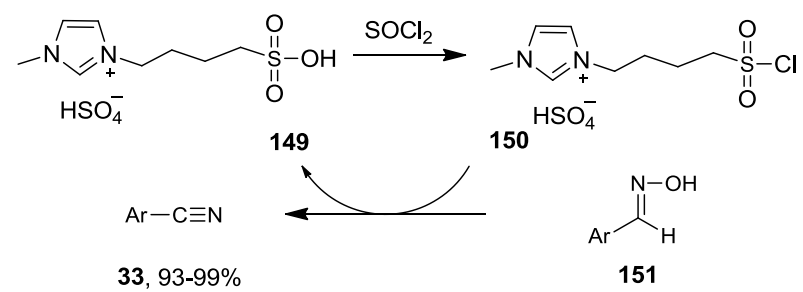

$\mathrm{Ar}=2-\mathrm{BrC}_{6} \mathrm{H}_{4}, 3-\mathrm{BrC}_{6} \mathrm{H}_{4}, 4-\mathrm{ClC}_{6} \mathrm{H}_{4}, 4-\mathrm{NO}_{2} \mathrm{C}_{6} \mathrm{H}_{4}, 2-\mathrm{OHC}_{6} \mathrm{H}_{4}, \mathrm{C}_{3} \mathrm{H}_{7}$

Scheme 44: Synthesis of IL-supported sulfonyl chloride 150 and its application in dehydration of aldoximes.

\subsection{Ionic liquid-supported sulfonyl azide}

Wider utility of sulfonyl azides in organic synthesis and problems associated with their safety and purification of the product, encouraged us to synthesize a new ionic liquid-supported sulfonyl azide 155. ${ }^{112}$ Synthesis of $\mathbf{1 5 5}$ was achieved as shown in Scheme 45. Initially, the reaction of 1-methylimidazole $\mathbf{1 4}$ with 1,3-propanesultone $\mathbf{1 5 2}$ at $0{ }^{\circ} \mathrm{C}$ followed by acidification with trifluoromethanesulfonic acid (TfOH) at room temperature gave 153. Reaction of $\mathbf{1 5 3}$ with thionyl chloride under reflux conditions, followed by reaction with sodium azide afforded $\mathbf{1 5 5}$. The differential scanning calorimetry (DSC) analysis of $\mathbf{1 5 5}$ revealed that the exothermic decomposition temperature of pure $\mathbf{1 5 5}$ is above $150{ }^{\circ} \mathrm{C}$ and it is much higher compared to most of the traditional diazo transfer reagents.

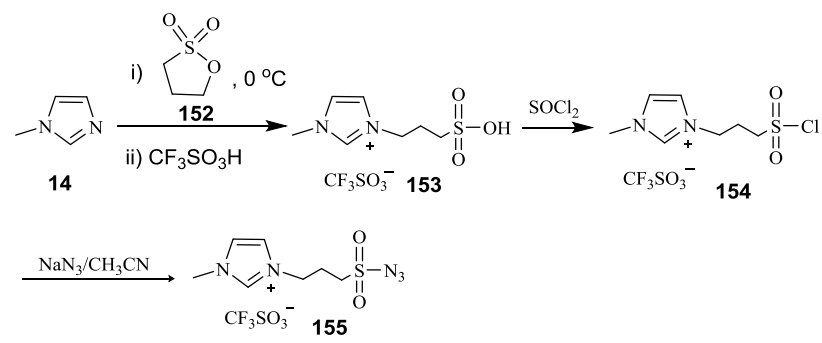

Scheme 45: Synthesis of IL-supported sulfonyl azide 155.

The scope of reagent $\mathbf{1 5 5}$ as a diazotransfer reagent was evaluated by treating it with various active methylene compounds like 1,3-diketones, $\beta$-ketoester, and 1,3-diesters 156 (Scheme 46). ${ }^{112}$ Reagent 155 afforded diazo compounds 157 in excellent yields with high purity under solvent free conditions in a short period. $\beta$-Ketosulfones that have been previously reported as poor substrates for the diazotransfer reaction gave corresponding diazo compounds in excellent yields with reagent 155. Moreover, 155 was also used as a detrifluoroacetylative diazotransfer reagent to synthesize 158 from 155. The products were isolated in the pure form by simple extraction with hexane-ethyl acetate mixture where as in the case of traditional sulfonyl azide product isolation proved to be tricky as it required repetitive column chromatography to remove tosylamide from the products.

$$
\begin{aligned}
& \mathrm{R}=\mathrm{Et}_{3} \mathrm{~N} \\
& \begin{array}{ll}
158,80-82 \% \\
\mathrm{EWG}=\mathrm{CF}_{3} \mathrm{CO}
\end{array}
\end{aligned}
$$

Scheme 46: Diazotransfer and detrifluoroacetylative diazotransfer reaction using $\mathbf{1 5 5}$.

\subsection{Nucleophilic Ionic liquids}

Nucleophilic ionic liquids (NILs) ${ }^{113}$ are a unique class of ionic liquid based reagents in which the anion of the ionic liquid acts as nucleophile. One common characteristic amongst these NILs are that the nucleophilicity of these anions is generally higher than that of their inorganic salts. The increase in nucelophilicity may be attributed to the presence of an ionic liquid. Similar effect of ionic liquid has been reported for fluorination by nucleophilic substitution, ${ }^{114}$ nucleophilic substitution of activated aryl halides with secondary amines, ${ }^{115}$ and reactivity of anionic nucleophiles in ionic liquids. ${ }^{116,} 117$ Synthesis of NILs 160-163 has been achieved by the anion metathesis of halide ion of ionic liquid $\mathbf{1 5 9}$ using corresponding sodium or potassium salts (Scheme 47).

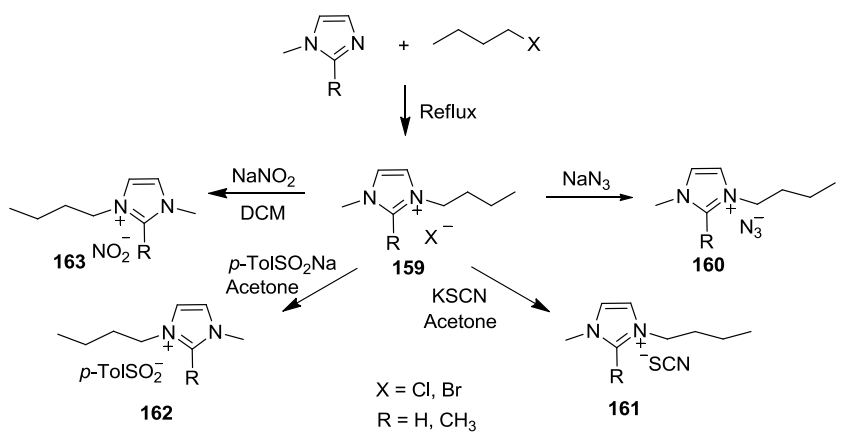

Scheme 47: Synthesis of nucleophilic ionic liquids.

Anna et al. were the first to report the use of $[\mathrm{bmim}]\left[\mathrm{N}_{3}\right]$ 160 in aromatic nucleophilic substitution reaction $\left(S_{N} A r\right)$ (Scheme 48). ${ }^{51}$ A comprehensive discussion of solvent effect and substrate scope revealed interesting aspects of the reaction. Hydrogen bond donor ability $(\alpha)$ of the solvent played a key role in the outcome of the reaction. It was found that high $\alpha$ disfavours the reaction by stabilizing the nucleophile through coordination. Better yield of aryl azides 164 were obtained by using 160 in $[\mathrm{bmim}]\left[\mathrm{BF}_{4}\right]$ compared to $\mathrm{NaN}_{3}$ in $\mathrm{MeOH}$. Also the acidic C2-proton of [bmim] ion in $[\mathrm{bmim}]\left[\mathrm{BF}_{4}\right]$ coordinates with the $\mathrm{N}_{3}{ }^{-}$ion and decrease its 
nucleophilicity. Replacing C2-proton with the methyl group in $\left[\mathrm{bm}_{2} \mathrm{im}\right]\left[\mathrm{N}_{3}\right]$ and using $\left[\mathrm{bm}_{2} \mathrm{im}\right]\left[\mathrm{NTf}_{2}\right]$ as solvent improved the yield of aryl azides.

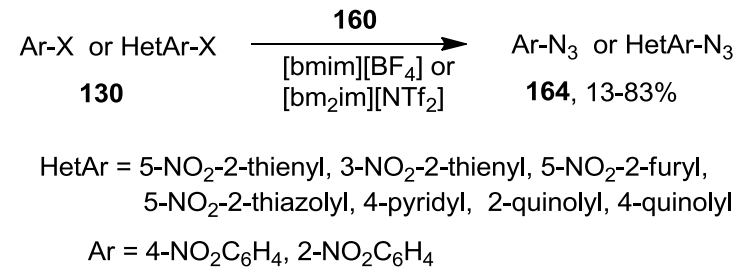

Scheme 48: Aromatic nucleophilic substitution reaction using $[\mathrm{bmim}]\left[\mathrm{N}_{3}\right] \&\left[\mathrm{bm}_{2} \mathrm{im}\right]\left[\mathrm{N}_{3}\right]$.

Heidarizadeh and co-workers described the synthesis of a novel protic azido functionalized nucleophilic ionic liquid 166 from 1-methylimidazole 21 (Scheme 49). ${ }^{118}$ The reaction of $\mathbf{2 1}$ with hydrochloric acid at room temperature gave 1-methyl-1H-imidazol-3-ium chloride 165 which on anion exchange with $\mathrm{NaN}_{3}$ in dry $\mathrm{CH}_{3} \mathrm{CN}$ resulted in $\mathbf{1 6 6}$. The nucleophilic ability of reagent $\mathbf{1 6 6}$ was evaluated for the ring opening of epoxides 167 to 1,2 -azidoalcohols $168 .{ }^{118} \mathrm{In}$ this reaction multiple-functions such as solvent, reagent and an activator were accomplished by $\mathbf{1 6 6}$. The acidic hydrogen of $\mathbf{1 6 6}$ activated the reaction, and azide anion acted as the nucleophilic source.

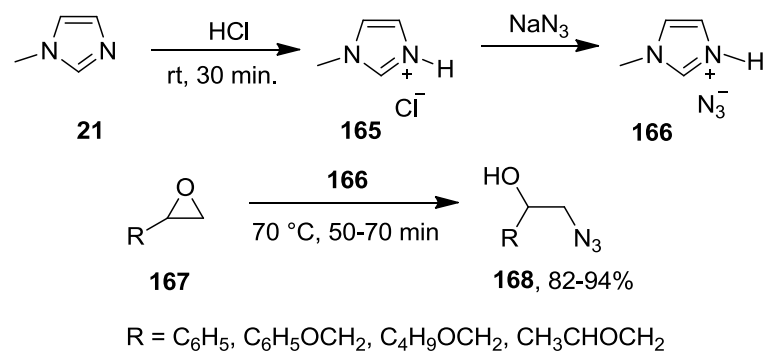

Scheme 49: Synthesis of NIL 166 and application in ring opening of epoxides.

Thiocyanate functionality is generally introduced via nucleophilic substitution reaction of alkyl halides with metal thiocyanates. ${ }^{119}$ Prolonged heating at $50{ }^{\circ} \mathrm{C}$ and the chromatographic purification with silica gel leads to the formation of thermodynamically favoured isothiocyanates. To overcome these difficulties, Kamal and Chouhan reported novel NILs [bmim] [SCN] 161. ${ }^{120}$ Reagent 161 was prepared by the anion exchange of $\mathbf{1 5 9}$ with $\mathrm{KSCN}$ in acetone. A variety of alkyl halides and substituted phenacyl bromides 9 were converted to corresponding alkyl thiocyanates 169 in high yields at room temperature using 161 under solvent free conditions (Scheme 50). In this reaction [bmim] $[\mathrm{SCN}]$ plays dual roles as reagent and solvent that obviates the necessity of additional solvent in the reaction mixture. Comparative study of a nucleophilic displacement reaction of alkyl halides was carried out using reagent 161 and KSCN. Complete conversion of 9 to $\mathbf{1 6 9}$ was observed when 161 was employed as the nucleophilic source whereas only $20-30 \%$ of $\mathbf{1 6 9}$ were formed in the case of KSCN.

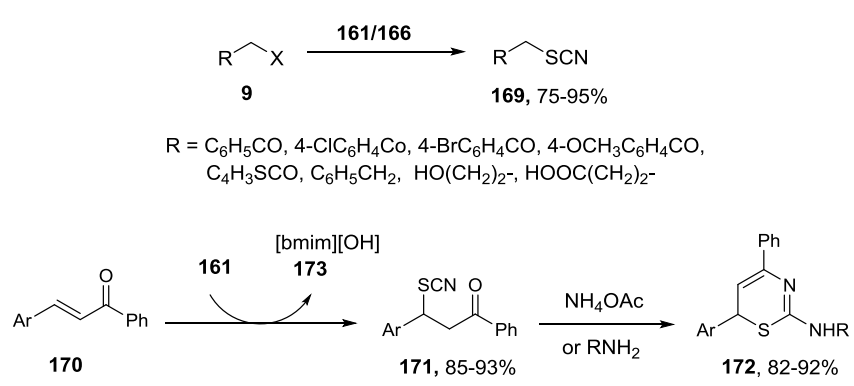

Scheme 50: Thiocyanation of alkyl halides and chalcones using [bmim][SCN].

To tune the solubility of nucleophilic ionic liquid with thiocyanate anion, Mohanazadeh and Aghvami synthesized a new ionic liquid 2-hydroxy- $N, N, N$-tributylethanaminium thiocyanate $\left[\mathrm{n}-\mathrm{Bu}_{3} \mathrm{NCH}_{2} \mathrm{CH}_{2} \mathrm{OH}\right][\mathrm{SCN}], \mathbf{1 7 5}$ by an anion metathesis from its corresponding bromide salt 174 (Scheme 51) ${ }^{121}$ Reagent $\mathbf{1 6 6}$ is soluble in acetone, chloroform, dichloromethane, and ethanol but insoluble in water, ether, and hexane. This differential solubility is very useful for the separation of product from the reaction mixture. Compound 175 has been used as a reagent and solvent in the synthesis of $\mathbf{1 6 9}$ from 9.

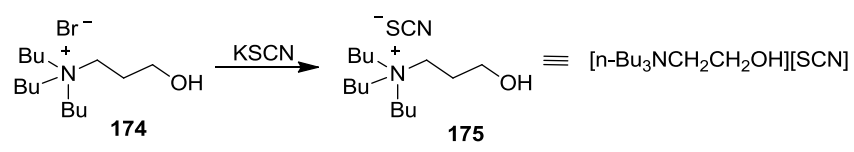

Scheme 51: Synthesis of [n- $\left.\mathrm{Bu}_{3} \mathrm{NCH}_{2} \mathrm{CH}_{2} \mathrm{OH}\right][\mathrm{SCN}]$.

Later, Yadav et al. developed an efficient method for conjugative hydro thiocyanation of chalcones $\mathbf{1 7 0}$ using 161 (Scheme 50). ${ }^{122}$ The superior nucleophilicity of $\mathbf{1 6 1}$ led to the formation of $\beta$-thiocyanato $\alpha, \beta$-unsaturated ketones 171 in very good yields (85-93\%). Compound $\mathbf{1 7 1}$ was further transformed to the pharmaceutically interesting molecule 2-amino-1,3-thiazines $\mathbf{1 7 2}$ by reacting with ammonium acetate or alkyl amines. The advantage of the method is easy purification and it does not require chromatographic separation and thus the possibility of rearrangement of thiocyanate to isothiocyanates was minimized. The reagent 161 could be recycled by treating co-product [bmim] $[\mathrm{OH}]$ 170 with conc. $\mathrm{HCl}$ followed by reaction with $\mathrm{KSCN}$ at room temperature.

We also reported the synthesis of a novel nucleophilic ionic liquid reagent $[\mathrm{bmim}]\left[p-\mathrm{TolSO}_{2}\right] \mathbf{1 6 2} .{ }^{123}$ Synthesis of $\mathbf{1 6 2}$ was achieved by the reaction of $[\mathrm{bmim}][\mathrm{Br}]$ with sodium $p$-toluenesulfinate $\left(p-\mathrm{TolSO}_{2} \mathrm{Na}\right)$ in acetone (Scheme 47). Furthermore, 162 was utilized for the synthesis of sulfones and $\beta$-ketosulfones $\mathbf{1 7 6}$ from alkyl and phenacyl bromides (Scheme 52). Detailed solvent study was carried out to find the best suitable solvent for the synthesis of $\mathbf{1 7 6} .{ }^{122}$ Of the solvents screened, $[\mathrm{bmim}]\left[\mathrm{BF}_{4}\right]$ was found to be most efficient due to its non-coordinating nature, while solvents like [bmim] $[\mathrm{Br}]$ and $\mathrm{CH}_{3} \mathrm{CN}$ did not result in the product formation. By comparing the yield of $\mathbf{1 7 6}$ using $p \mathrm{TolSO}_{2} \mathrm{Na}$ and reagent 162 in $[\mathrm{bmim}]\left[\mathrm{BF}_{4}\right]$, it was found that higher yields were obtained in case of $\mathbf{1 6 2}$. Thus, it is proposed that 
the nucleophilicity of $p$ - $\mathrm{TolSO}_{2}^{-}$ion is higher for $\mathbf{1 6 2}$ than that of $p$ - $\mathrm{TolSO}_{2} \mathrm{Na}$.

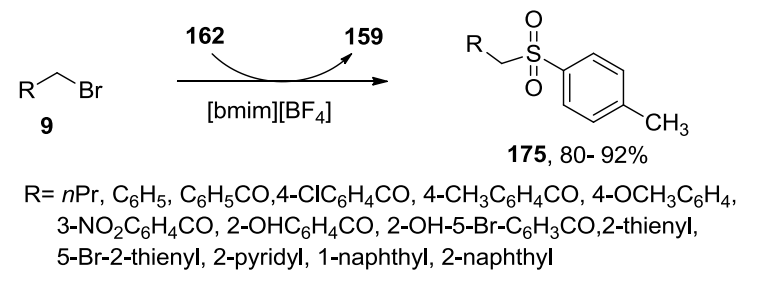

Scheme 52: Synthesis of sulfones and $\beta$-ketosulfones from using [bmim] $\left[p-\mathrm{TolSO}_{2}\right]$.

\subsection{Ionic liquid-supported quinuclidine}

Cheng et al. have synthesized quinuclidine-functionalized ionic liquids 181. ${ }^{124,}{ }^{125}$ The target ionic liquids $\mathbf{1 8 1}$ were obtained as shown in Scheme 53. Initially, quaternization of imidazoles 176 with 4-bromobutyl amine 177 gave amino-functionalized ionic liquid 178. Reductive amination of 178 with quinuclidin-3-one 179 gave $180 a^{\prime}-\mathbf{a c}^{\prime}$ that on further anion exchange with $\mathrm{NaBF}_{4}$ or $\mathrm{KPF}_{6}$ led to $180 \mathbf{b a}^{\prime}-$ bc $^{\prime}$ and $180 \mathbf{c a}^{\prime}-\mathbf{c c}^{\prime}$, respectively.

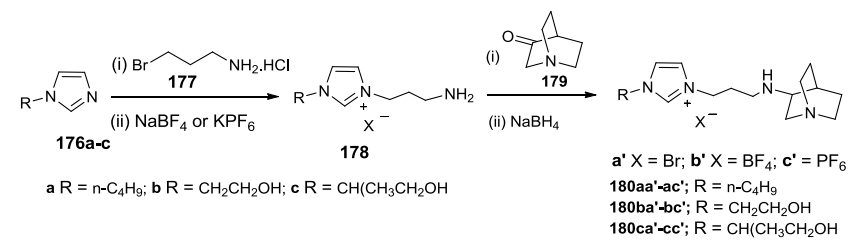

Scheme 53: Synthesis of quinuclidine-functionalized ionic liquids $\mathbf{1 8 1}$.

Morita-Baylis-Hillman (MBH) reaction is an efficient and simple carbon-carbon bond forming reactions in organic synthesis. Stoichiometric amount of Lewis bases such as DABCO, DBU, DMAP, $\mathrm{PPh}_{3}$ and imidazole are required to facilitate the $\mathrm{MBH}$ reaction. ${ }^{126,127}$ To solve the problems associated with the recovery and reuse of Lewis base $\mathbf{1 8 0}$ was used as homogeneous catalysts in the MBH reaction of aldehydes 47 with alkenes 131 (Scheme 54). Of all the solvents screened for the $\mathrm{MBH}$ reaction, polar protic solvents like methanol proved to be the most efficient. Further examination revealed that the amount of methanol also had a pronounced effect on the yield of $\mathbf{1 8 1}$ and optimal yield was achieved when 180ab' was employed with two equiv of methanol in the reaction mixture (Scheme 54, Method A). When ionic liquids $[\mathrm{bmim}]\left[\mathrm{BF}_{4}\right]$, [bmim] $\left[\mathrm{PF}_{6}\right]$, [bupy] $\left[\mathrm{BF}_{4}\right]$ and $[\mathrm{bmmim}]\left[\mathrm{BF}_{4}\right]$ were used as solvents the yields of 181 were found to be substantially lower than those in methanol. Remarkably, the catalyst 180ab' was equally efficient for poor substrates like cyclicenones and $p$-methoxybenzaldehyde. Moreover, 181b exhibited much better catalytic activity than some well known Lewis bases such as 3-quinuclidinone and DABCO under the given reaction conditions.

Quinclidine functionalized ionic liquid with a hydroxyl group in alkyl side chain 180ba'-bc' and 180ca'-cc' showed higher catalytic activity as compared to the non hydroxyl counterpart 180aa'-ac' even at lower catalyst loading (20 mol \%) under solvent free conditions (Scheme 54, method A $v s$ method B). This is attributed to hydrogen bond activation and/or the promotion of intramolecular proton transfer by

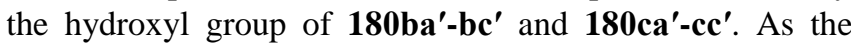
catalyst offered a homogenous reaction and heterogeneous separation 180 can be easily separated from the products and reused at least six times without significant loss of activity. Moreover, MBH reactions of $N$-sulfonated imines 135 with various substrates such as methyl acrylate and acrylonitrile were promoted to give exclusively the desired adducts $\mathbf{1 3 6}$ (Scheme 37, method B \& C).

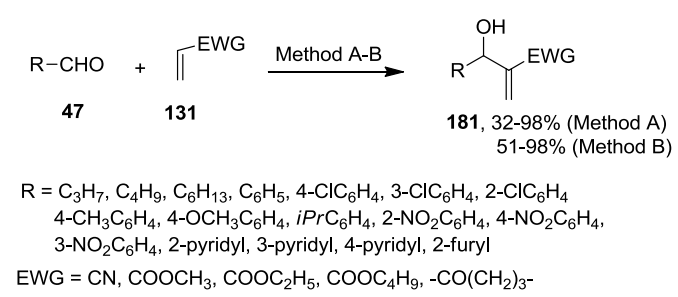

Method A: 180ab' (0.3 equiv), MeOH (2 equiv), $62-98 \%$ Method B: $180 \mathrm{ca}$ ( 0.2 equiv)

Scheme 54: Morita-Baylis-Hillman reaction catalysed by 180.

\section{Functionalized ionic liquid as scavengers}

\subsection{Amino functionalized ionic liquids}

Song and group synthesized amino functionalized ionic liquid 183 by n-alkylation of 1-methylimidazole 14 with 2-bromoethylamine hydrobromide $\mathbf{1 8 2}$, followed by anion exchange with $\mathrm{KPF}_{6}$ and neutralization with $\mathrm{NaOH}$ (Scheme 55). ${ }^{56}$ They further demonstrated the application of $\mathbf{1 8 3}$ as scavengers to remove excess of electrophiles like $p$-toluenesulfonyl chloride, acid chlorides, isothiocyanate, and isocyanates from the reaction mixture (Figure 2).

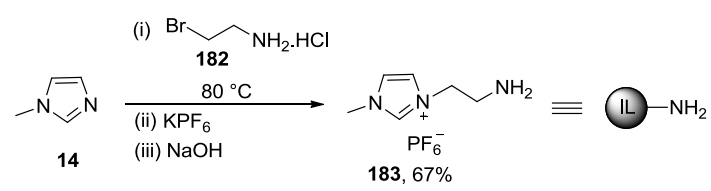

Scheme 55: Synthesis of amino functionalized ionic liquid.

Due to the viscous nature of $\mathbf{1 8 3}$, a longer time (over $9 \mathrm{~h}$ ) was required to scavenge $p$-toluenesulfonyl chloride from a toluene solution (Figure 2). Addition of conventional ionic liquid $[\mathrm{bmim}]\left[\mathrm{PF}_{6}\right]$ into the reaction mixture dramatically enhanced the scavenging process $(35 \mathrm{~min})$. The large difference in special gravity and high interfacial tension between ionic liquid phase ([bmim] $\left[\mathrm{PF}_{6}\right], \mathbf{1 8 3}$, and organic solvents (toluene) caused the phase separation. The electrophile-free organic phase was separated by decantation, and the pure compound was extracted using $\mathrm{CH}_{2} \mathrm{Cl}_{2} / \mathrm{Et}_{2} \mathrm{O}$ from ionic liquid phase. A small library of aromatic esters has been synthesized from various benzoyl chlorides with different phenols using $\mathbf{1 8 3}$ as scavenger. The products were obtained in high yields $(>97 \%)$ and purity $(>97 \%)$. Moreover, the reagent 183 was regenerated and reused for three cycles with comparable activity. 


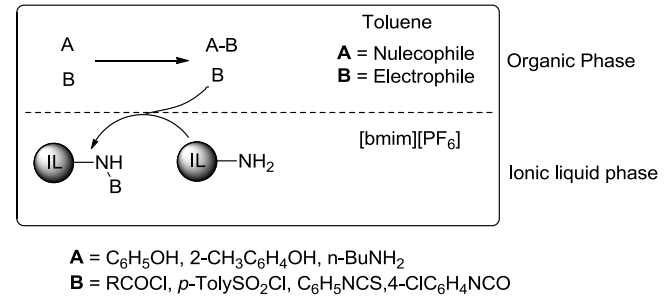

Figure 2: Scavenging of electrophiles using 183.

Davis and co-workers have used amino functionalized ionic liquid 180ab' as a recyclable scavenger for carbon dioxide. ${ }^{128}$ In general, aqueous amines are used for the removal of carbon dioxide from natural gas. Conversely, in these systems, the uptake of the volatile amine sequestering agent and water into the gas stream is problematic. To deal with these problems Davis group used 180ab' to capture $\mathrm{CO}_{2}$ as carbamate 184 (Scheme 56). The molar uptake of $\mathrm{CO}_{2}$ per mole of $\mathbf{1 8 0} \mathbf{a b}^{\prime}$ was close to 0.5 , which is the theoretical maximum for $\mathrm{CO}_{2}$ as an ammonium carbamate. Moreover, the uptake of $\mathbf{1 8 0} \mathbf{a b}^{\prime}$ is comparable to the regular sequestering amines, such as diisopropanolamine (DIPA), $\beta, \beta^{\prime}$-hydroxyaminoethyl ether (DGA), and monoethanolamine (MEA). The process is reversible and $\mathrm{CO}_{2}$ could be expelled from the $\mathbf{1 8 4}$ by heating in vacuum. The recovered ionic liquid $\mathbf{1 8 0} \mathbf{a b}^{\prime}$ can be reused for five cycles effectively. FT-IR and NMR spectroscopic techniques were used to analyze the gas-treated ionic liquid.

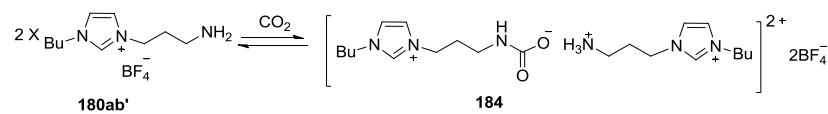

Scheme 56: Scavenging of $\mathrm{CO}_{2}$ as carbamate using 180ab'.

\subsection{Carboxyl functionalized ionic liquids}

Song and group have also synthesized a carboxyl functionalized ionic liquid $\mathbf{1 8 6}$ from 1-methylimidazole $\mathbf{1 4}$ as shown in Scheme 57. The reaction of $\mathbf{1 4}$ with chloroacetic acid $\mathbf{1 8 5}$ followed by anion exchange with $\mathrm{KPF}_{6}$ or $\mathrm{NaBF}_{4}$ resulted in corresponding carboxyl functionalized ionic liquid $\mathbf{1 8 6} .{ }^{55}$

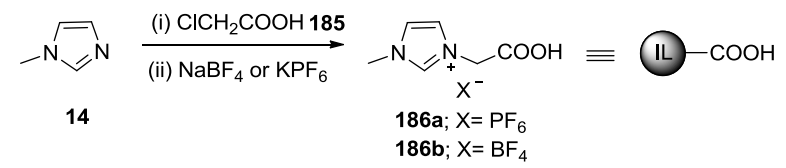

Scheme 57: Synthesis of carboxyl functionalized ionic liquid.

Reagent 186 was used as a scavenger for the removal of excess of materials present in the reaction mixture of the synthesis of sulfonyl esters, amides and acid anhydrides (Figure 3). ${ }^{55}$ The products were isolated in pure form by simple decantation of toluene, followed by extraction with $\mathrm{CH}_{2} \mathrm{Cl}_{2} / \mathrm{Et}_{2} \mathrm{O}$. The generality of the method was further extended by employing $\mathbf{1 8 6}$ in the synthesis of $N$-acyl- $N$-alkylpiperazines. Also 186 was regenerated by the hydrolysis of the ionic phase and recycled thrice without any marked decrease in activity.

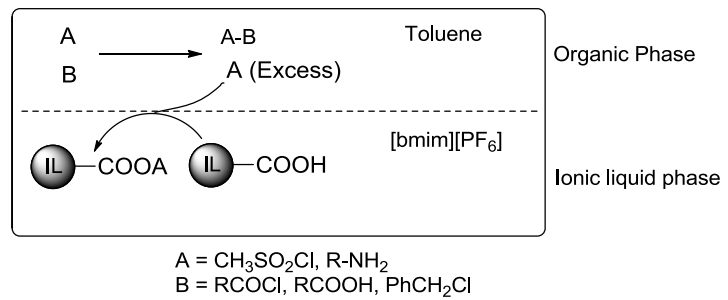

Figure 3: Scavenging of excess benzyl chlorides, sulfonyl chlorides, and amines using $\mathbf{1 8 6}$.

\subsection{Aldehyde functionalized ionic liquid}

Reductive amination is a powerful tool for synthesis of structurally diverse secondary amines that are used in high throughput synthesis. Over alkylation is the main concern in reductive amination process, which leads to the formation of tertiary amines. Excess of primary amine has been employed to prevail over alkylation. ${ }^{129,130}$ The excess amine has to be removed by tedious column chromatography or traditional distillations in order to get pure compounds. These techniques are often time consuming, labor-intensive, expensive process, and may not result always in a pure compound. To overcome these problems, recently our group designed and synthesized an aldehyde functionalized ionic liquid 189. ${ }^{131}$ Synthesis of $\mathbf{1 8 9}$ was achieved in three steps as shown in Scheme 58. Initially, $O$-alkylation of 4-hydroxybenzaldehyde with 1-bromo-3-chloropropane $\mathbf{1 2}$ gave 4-(3-chloropropoxy)benzaldehyde 188. Reaction of 188 with 14 followed by anion exchange with $\mathrm{NaBF}_{4}$ or $\mathrm{KPF}_{6}$ afforded desired ionic liquids $\mathbf{1 8 9}$.

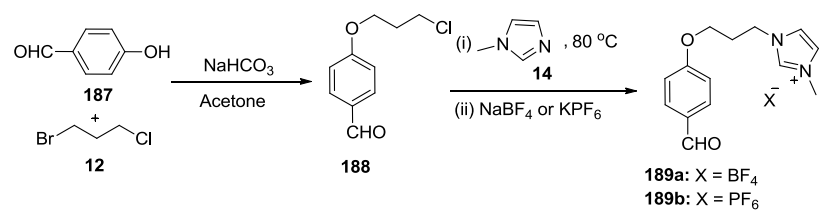

Scheme 58: Synthesis of aldehyde functionalized ionic liquid.

Scavenging of excess amines in the synthesis of secondary amines was studied using 189 (Scheme 59). A self induced phase separation of the reaction mixture was observed when 189b was used as scavenger, which led to simple and effortless isolation of the products from reaction mixture by simple filtration. A small library of secondary amines 191 was synthesized in high yields (82-90\%) with excellent purity. Reagent 189b can be regenerated and reused effectively without much loss in the activity.

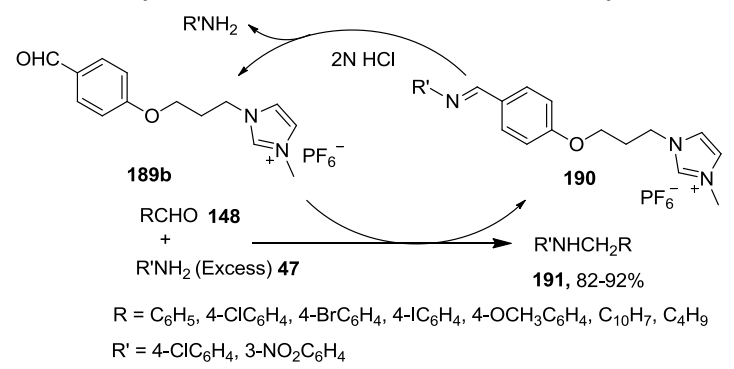

Scheme 59: Scavenging of amines using 189. 
Huang group has synthesized three aldehyde functionalized ionic liquids and these aldehyde functionalized ionic liquids were easily transformed to corresponding carboxyl functionalized ionic liquids, benzylic alcohol functionalized

Table 1: Capture and release of aldehydes in the presence of ketones using diol-functionalized ionic liquid 193.

\begin{tabular}{|c|c|c|c|c|c|c|c|}
\hline Entry & Mixture & \% Capture & $\begin{array}{l}\% \\
\text { Release }\end{array}$ & Entry & Mixture & \% Capture & $\begin{array}{l}\% \\
\text { Release }\end{array}$ \\
\hline \multirow[t]{2}{*}{1} & $\mathrm{C}_{6} \mathrm{H}_{5} \mathrm{CHO}$ & 100 & 92 & 5 & $\mathrm{C}_{6} \mathrm{H}_{5} \mathrm{CHO}$ & 100 & 93 \\
\hline & $\mathrm{C}_{6} \mathrm{H}_{5} \mathrm{COCH}_{3}$ & 0 & 0 & & $4-\mathrm{BrC}_{6} \mathrm{H}_{5} \mathrm{OCH}_{3}$ & 0 & 0 \\
\hline \multirow[t]{2}{*}{2} & $2,6-(\mathrm{Cl})_{2} \mathrm{C}_{6} \mathrm{H}_{3} \mathrm{CHO}$ & 100 & 91 & 6 & $2-\mathrm{ClC}_{6} \mathrm{H}_{4} \mathrm{CHO}$ & 100 & 92 \\
\hline & $\mathrm{C}_{6} \mathrm{H}_{5} \mathrm{COCH}_{3}$ & 0 & 0 & & $4-\mathrm{BrC}_{6} \mathrm{H}_{5} \mathrm{OCH}_{3}$ & 0 & 0 \\
\hline \multirow[t]{2}{*}{3} & $2,6-(\mathrm{Cl})_{2} \mathrm{C}_{6} \mathrm{H}_{3} \mathrm{CHO}$ & 100 & 90 & 7 & $2,6-(\mathrm{Cl})_{2} \mathrm{C}_{6} \mathrm{H}_{3} \mathrm{CHO}$ & 100 & 90 \\
\hline & $\mathrm{C}_{2} \mathrm{H}_{5} \mathrm{COC}_{4} \mathrm{H}_{9}$ & 0 & 0 & & 4- $\mathrm{BrC}_{6} \mathrm{H}_{5} \mathrm{OCH}_{3}$ & 0 & 0 \\
\hline \multirow[t]{2}{*}{4} & $2,6-(\mathrm{Cl})_{2} \mathrm{C}_{6} \mathrm{H}_{3} \mathrm{CHO}$ & 100 & 91 & 8 & $2,6-(\mathrm{Cl})_{2} \mathrm{C}_{6} \mathrm{H}_{3} \mathrm{CHO}$ & 63 & 92 \\
\hline & Cyclohexanone & 0 & 0 & & $\mathrm{C}_{6} \mathrm{H}_{5} \mathrm{CHO}$ & 37 & 0 \\
\hline
\end{tabular}

\subsection{Diol-functionalized ionic liquid}

Cai and Liu reported synthesis of a novel diol-functionalized ionic liquid, 2,2-bis(1-(1-methylimidazolium)methylpropane -1,3-diol hexafluorophosphate 193. ${ }^{57}$ Synthesis of $\mathbf{1 9 3}$ has been achieved as shown in Scheme 60. Reaction of 14 with 2,2-bis(bromomethyl)-1,3-propanediol $\mathbf{1 9 2}$ at $150{ }^{\circ} \mathrm{C}$, followed by anion exchange with $\mathrm{NH}_{4} \mathrm{PF}_{6}$ yielded diol functionalized ionic liquid 193.

$$
\begin{aligned}
& 2 \mathrm{X}-\mathrm{N}=\mathrm{N}+\overbrace{\mathrm{OH}}^{\stackrel{\mathrm{Br}}{\mathrm{Br}}} \stackrel{\text { (i) } 150^{\circ} \mathrm{C}}{\mathrm{NH}_{4} \mathrm{PF}_{6}} \\
& 14192
\end{aligned}
$$

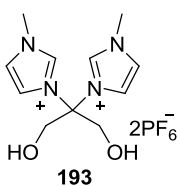

Scheme 60: Synthesis of diol functionalized ionic liquid.

The capture and release studies of different aldehydes were studied using 193 (Scheme 61). The aldehydes were selectively captured as 1,3-dioxane 194 when a mixture of aldehydes and ketones was treated with $\mathbf{1 9 3}$ in the presence of $\mathrm{TiCl}_{4}$ (Table 1, entry 1-4). The captured aldehydes were further released by the hydrolysis of $\mathbf{1 9 4}$ in the presence of $\mathrm{TsOH}$ and recovered $\mathbf{1 9 3}$ was reused four times without significant loss of activity. ${ }^{57}$

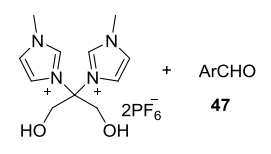

193

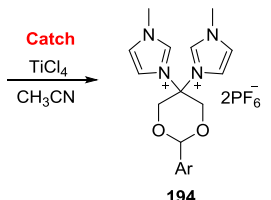

194

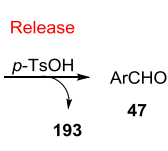

93
Scheme 61: Capture and release of aldehydes using 193.

\subsection{Ionic liquid functionalized with Michael acceptors}

The removal of malodorous and toxic volatile sulfur compounds is a major concern in oil refineries, food processing and in paper mills. Gunaratne et al. have synthesized trialkylammonium and alkylpyridinium based ionic liquids, hydrazone functionalized ionic liquids, and secondary amine functionalized ionic liquids. ${ }^{132}$ three ionic liquids functionalized with Michael acceptors 200, 201 and 203 for scavenging thiols and hydrogen sulfide. ${ }^{133}$ Synthesis of ionic liquids 200 and 201 was achieved from ethyl cyanoacetate $\mathbf{1 9 5}$ as shown in scheme 62. Reaction of $\mathbf{1 9 5}$ with pyridine carboxaldehyde 196 and functionalized benzaldehyde 197 followed by quaternization with dimethyl sulfate or ethylmethyl sulfate resulted in formation of ionic liquids 200 and 201, respectively. On the other hand ionic liquid $\mathbf{2 0 3}$ was synthesized from 2-(dimethylamino)ethyl acrylate $\mathbf{2 0 2}$ by quaternization with ethyl iodide followed by anion exchange with $\mathrm{Li}\left[\mathrm{N}\left(\mathrm{SO}_{2} \mathrm{CF}_{3}\right)_{2}\right]$. The ionic liquids 200, 201 and 203 have been used as Michael acceptors for the scavenging of thiols and hydrogen sulfide. Among these three ionic liquids 203 has shown superior reactivity as scavenger for thiols and $\mathrm{H}_{2} \mathrm{~S}$. The non-volatile nature, easy phase separation and masking the malodors property of volatile sulfur compounds are the main advantageous of these ionic liquids.

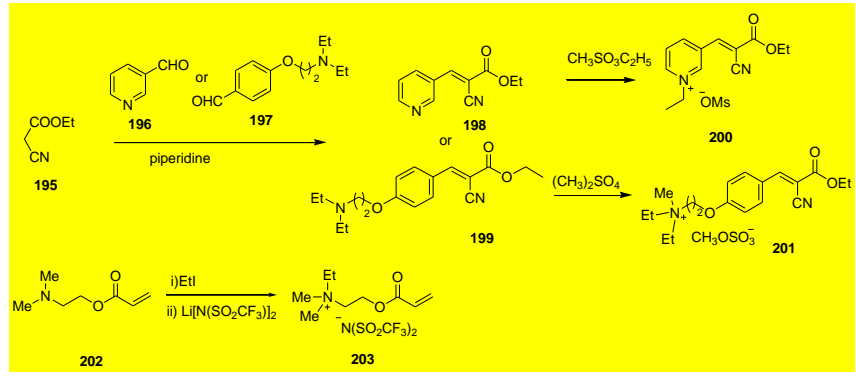

Scheme 62: Synthesis of ionic liquids 200, $201 \& 203$.

\subsection{Silica-supported sulfonic acid functionalized ionic liquid}

To overcome the separation issues due to solubility of some of the ionic liquid-supported scavengers, Song and his group synthesized a heterogeneous silica-supported sulfonic acid functionalized ionic liquid $\mathrm{Si}$-[SbSipim] $\left[\mathrm{PF}_{6}\right] \quad \mathbf{2 0 8}^{134}$ Synthesis of 208, was achieved by sequential reaction of 
silica with (3-chloropropyl)trimethoxysilane 205, imidazole 14 and 1,4-butanesultone $\mathbf{7 2}$ followed by neutralization with trifloromethanesulfonic acid and anion exchange with $\mathrm{PF}_{6}$ (Scheme 63).

Reagent 208 was utilized for the scavenging of excess amines during synthesis of amides and sulfonamides. It was found that scavenging of anilines in toluene using reagent 208 was sluggish and took longer time $(>10 \mathrm{~h})$. This longer scavenging time may be due to the heterogeneous nature of reagent 208. However, use of 209 with a coating of conventional ionic liquid $[\mathrm{bmim}]\left[\mathrm{PF}_{6}\right]$ on to the reagent 208 has dramatically shortened the scavenging process time (100 min). Using this strategy small library of amides and sulfonamides has been synthesized in excellent yields (96-98\%) with high purity $(>97.6 \%)$. The reagent can be regenerated and reused effectively several times without much significant difference in activity.

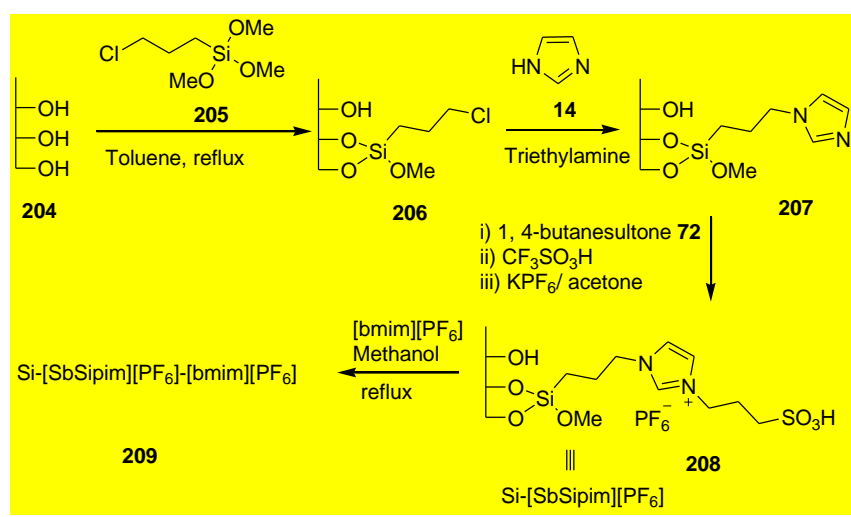

Scheme 63: Synthesis of silica-supported sulfonic acid functionalized ionic liquids $208 \& 209$.

\section{Conclusion}

The excellent articles published on the use of FILs as reagents in various organic transformations in the last decade are underpinning their importance and great potential in organic synthesis. FILs have provided efficient ways of addressing some of the disadvantages of solid-phase synthesis. They have offered advantages of increased loading of the reagent, fast reaction times in homogeneous environments, easy intermediate analysis using modern techniques, and ready adaptability to literature conditions. Enormous range of combinations with tailor-made properties could be synthesized by varying the anions and cations. These materials have apparent advantages over other soluble supports such as PEG and perfluorinated compounds.

The application of functionalized ionic liquids (FILs) as reagents and scavengers in organic synthesis are still in the early stage of development. The linker strategy developed for solid-phase synthesis and fluorous phase synthesis can be applied to ionic liquids to generate new functionalized ionic liquids. With increased availability of functionalized ionic liquids, they should find applications in the synthesis of complex molecules and biomolecules.

\section{References}

1 Hodge, P. Polymer-supported organic reactions: what takes place in the beads? Chem. Soc. Rev., 1997, 26, $417-424$

2 Sloan, L. A.; Procter, D. J. Lanthanide reagents in solid phase synthesis. Chem. Soc. Rev., 2006, 35, 1221-1229.

3 Ruck-Braun, K.; Freysoldt, T. H. E.; Wierschem, F. 1,3-Dipolar cycloaddition on solid supports: nitrone approach towards isoxazolidines and isoxazolines and subsequent transformations. Chem. Soc. Rev., 2005, 34, 507-516

4 C. D. Brown, R. Recent developments in solid-phase organic synthesis. J. Chem. Soc., Perkin Trans. 1, 1998, 3293-3320.

5 Seeberger, P. H.; Haase, W.-C. Solid-Phase Oligosaccharide Synthesis and Combinatorial Carbohydrate Libraries. Chem. Rev., 2000, 100, 4349-4394.

6 Boas, U.; Brask, J.; Jensen, K. J. Backbone Amide Linker in Solid-Phase Synthesis. Chem. Rev., 2009, 109, 2092-2118.

7 Lorsbach, B. A.; Kurth, M. J. Carbon-Carbon Bond Forming Solid-Phase Reactions. Chem. Rev., 1999, 99, $1549-1582$.

8 Guillier, F.; Orain, D.; Bradley, M. Linkers and Cleavage Strategies in Solid-Phase Organic Synthesis and Combinatorial Chemistry. Chem. Rev., 2000, 100, 2091-2158.

9 Sammelson, R. E.; Kurth, M. J. Carbon-Carbon Bond-Forming Solid-Phase Reactions. Part II. Chem. Rev., 2000, 101, 137-202.

10 Booth, S.; Hermkens, P. H. H.; Ottenheijm, H. C. J.; Rees, D. C. Solid-phase organic reactions III: A review of the literature Nov 96-Dec 97. Tetrahedron, 1998 $54,15385-15443$.

11 Hermkens, P. H. H.; Ottenheijm, H. C. J.; Rees, D. Solid-phase organic reactions: A review of the recent literature. Tetrahedron, 1996, 52, 4527-4554. 
12 Merrifield, R. B. Solid Phase Peptide Synthesis. I. The Synthesis of a Tetrapeptide. J. Am. Chem. Soc., 1963, $85,2149-2154$.

13 Hlaváč, J.; Soural, M.; Krchňák, V. In Practical Aspects of Combinatorial Solid-Phase Synthesis; John Wiley \& Sons, Inc., 2011. pp 95-130.

14 Crowley, J. I.; Rapoport, H. Solid-phase organic synthesis: novelty or fundamental concept? Acc. Chem. Res., 1976, 9, 135-144.

15 Lu, J.; Toy, P. H. Organic Polymer Supports for Synthesis and for Reagent and Catalyst Immobilization. Chem. Rev., 2009, 109, 815-838.

16 Blaney, P.; Grigg, R.; Sridharan, V. Traceless Solid-Phase Organic Synthesis. Chem. Rev., 2002, 102, 2607-2624.

17 Varma, R. S. Solvent-free organic syntheses . using supported reagents and microwave irradiation. Green Chem., 1999, 1, 43-55.

18 Fey, T.; Fischer, H.; Bachmann, S.; Albert, K.; Bolm, C. Silica-Supported TEMPO Catalysts: Synthesis and Application in the Anelli Oxidation of Alcohols. J. Org. Chem., 2001, 66, 8154-8159.

19 Michaud, A.; Gingras, G.; Morin, M.; Béland, F.; Ciriminna, R.; Avnir, D.; Pagliaro, M. SiliaCat TEMPO: An Effective and Useful Oxidizing Catalyst. Org. Process Res. Dev., 2007, 11, 766-768.

20 Varma, R. S. Clay and clay-supported reagents in organic synthesis. Tetrahedron, 2002, 58, 1235-1255.

21 Gravert, D. J.; Janda, K. D. Organic Synthesis on Soluble Polymer Supports: Liquid-Phase Methodologies. Chem. Rev., 1997, 97, 489-510.

22 Sieber, F.; Wentworth, P.; Toker, J. D.; Wentworth, A. D.; Metz, W. A.; Reed, N. N.; Janda, K. D. 33 Development and Application of a Poly(ethylene glycol)-Supported Triarylphosphine Reagent: Expanding the Sphere of Liquid-Phase Organic Synthesis. J. Org. Chem., 1999, 64, 5188-5192.

23 Toy, P. H.; Janda, K. D. Soluble Polymer-Supported Organic Synthesis. Acc. Chem. Res., 2000, 33,
$546-554$

24 Wipf, P.; Venkatraman, S. An improved protocol for azole synthesis with PEG-supported Burgess reagent. Tetrahedron Lett., 1996, 37, 4659-4662.

25 Wentworth, A. D.; Wentworth, P.; Mansoor, U. F.; Janda, K. D. A Soluble Polymer-Supported Triflating Reagent: A High-Throughput Synthetic Approach to Aryl and Enol Triflates. Org. Lett., 2000, 2, 477-480.

26 Wentworth Jr, P.; D. Janda, K. Liquid-phase chemistry: recent advances in soluble polymer-supported catalysts, reagents and synthesis. Chem. Commun., 1999 1917-1924.

27 Miura, T.; Goto, K.; Hosaka, D.; Inazu, T. Oligosaccharide Synthesis on a Fluorous Support Angew. Chem. Int. Ed., 2003, 42, 2047-2051.

28 Chen, C.-T.; Zhang, W. Fluorous reagents and scavengers versus solid-supported reagents and scavengers, a reaction rate and kinetic comparison. Mol. Divers., 2005, 9, 353-359.

29 Zong, C.; Venot, A.; Dhamale, O.; Boons, G.-J. Fluorous Supported Modular Synthesis of Heparan Sulfate Oligosaccharides. Org. Lett., 2013, 15, 342-345.

30 Dobbs, A. P.; Kimberley, M. R. Fluorous phase chemistry: a new industrial technology. J. Fluorine Chem., 2002, 118, 3-17.

31 Zhang, W. Fluorous Linker-Facilitated Chemical Synthesis. Chem. Rev., 2009, 109, 749-795.

32 Thompson, L. A. Recent applications of polymer-supported reagents and scavengers in combinatorial, parallel, or multistep synthesis. Curr. Opin. Chem. Biol., 2000, 4, 324-337.

Ley, S. V.; Leach, A. G.; Storer, R. I. A polymer-supported thionating reagent. J. Chem. Soc., Perkin Trans. 1, 2001, 358-361.

34 V. Ley, S.; Schucht, O.; W. Thomas, A.; John Murray, P. Synthesis of the alkaloids (+/-)-oxomaritidine and (+/-)-epimaritidine using an orchestrated multi-step sequence of polymer supported reagents. J. Chem. Soc., 
Perkin Trans. 1, 1999, 1251-1252.

Dickerson, T. J.; Reed, N. N.; Janda, K. D. Soluble Polymers as Scaffolds for Recoverable Catalysts and Reagents. Chem. Rev., 2002, 102, 3325-3344. phase separation techniques in catalysis. Chem. Soc. Rev., 1999, 28, 37-41.

37 Berger, R.; Resnati, G.; Metrangolo, P.; Weber, E.; Hulliger, J. Organic fluorine compounds: A great opportunity for enhanced materials properties. Chem. Soc. Rev., 2011, 40, 3496-3508.

38 Tang, S.; Baker, G. A.; Zhao, H. Ether- and alcohol-functionalized task-specific ionic liquids: attractive properties and applications. Chem. Soc. Rev., 2012, 41, 4030-4066.

39 Jain, N.; Kumar, A.; Chauhan, S.; Chauhan, S. M. S. Chemical and biochemical transformations in ionic liquids. Tetrahedron, 2005, 61, 1015-1060.

40 Plechkova, N. V.; Seddon, K. R. Applications of ionic liquids in the chemical industry. Chem. Soc. Rev., 2008, 37, 123-150.

41 Wasserscheid, P.; Keim, W. Ionic Liquids-New "Solutions" for Transition Metal Catalysis. Angew. Chem. Int. Ed., 2000, 39, 3772-3789.

42 Welton, T. Room-Temperature Ionic Liquids. Solvents for Synthesis and Catalysis. Chem. Rev., 1999, 99, 2071-2084.

43 Hallett, J. P.; Welton, T. Room-Temperature Ionic Liquids: Solvents for Synthesis and Catalysis. 2. Chem. Rev., 2011, 111, 3508-3576.

44 Martins, M. A. P.; Frizzo, C. P.; Moreira, D. N.; Zanatta, N.; Bonacorso, H. G. Ionic Liquids in Heterocyclic Synthesis. Chem. Rev., 2008, 108, 56 2015-2050.

45 Hua Zhao, S. V. M. Applications of Ionic Liquids in Organic Synthesis. Aldrichimica Acta, 2002, 35, 75-83.

46 Davis, J. J. H. Task-Specific Ionic Liquids. Chem. Lett., $33,1072-1077$
47 Giernoth, R. Task-Specific Ionic Liquids. Angew. Chem. Int. Ed., 2010, 49, 2834-2839.

48 Plaquevent, J.-C.; Levillain, J.; Guillen, F. d. r.; Malhiac, C.; Gaumont, A.-C. Ionic Liquids: New Targets and Media for $\alpha$-Amino Acid and Peptide Chemistry. Chem. Rev., 2008, 108, 5035-5060.

49 Huo, C.; Chan, T. H. A novel liquid-phase strategy for organic synthesis using organic ions as soluble supports. Chem. Soc. Rev., 2010, 39, 2977-3006.

50 Zolfigol, M. A.; Khazaei, A.; Moosavi-Zare, A. R.; Zare, A.; Kruger, H. G.; Asgari, Z.; Khakyzadeh, V.; Kazem-Rostami, M. Design of Ionic Liquid 3-Methyl-1-sulfonic Acid Imidazolium Nitrate as Reagent for the Nitration of Aromatic Compounds by in Situ Generation of NO2 in Acidic Media. J. Org. Chem., 2012, 77, 3640-3645.

51 D’Anna, F.; Marullo, S.; Noto, R. Ionic Liquids/[bmim][N3] Mixtures: Promising Media for the Synthesis of Aryl Azides by SNAr. J. Org. Chem., 2008, 73, 6224-6228.

52 Pârvulescu, V. I.; Hardacre, C. Catalysis in Ionic Liquids. Chem. Rev., 2007, 107, 2615-2665.

53 Van Rantwijk, F.; Sheldon, R. A. Biocatalysis in Ionic Liquids. Chem. Rev., 2007, 107, 2757-2785.

54 Pucheault, M.; Vaultier, M. In Task Specific Ionic Liquids and Task Specific Onium Salts; Springer Berlin Heidelberg, 2010; Vol. 290. pp 83-126.

55 Cai, Y.; Zhang, Y.; Peng, Y.; Lu, F.; Huang, X.; Song, G. Carboxyl-Functional Ionic Liquids as Scavengers: Case Studies on Benzyl Chloride, Amines, and Methanesulfonyl Chloride. J. Comb. Chem., 2006, 8, 636-638

Song, G.; Cai, Y.; Peng, Y. Amino-Functionalized Ionic Liquid as A Nucleophilic Scavenger in Solution Phase Combinatorial Synthesis. J. Comb. Chem., 2005, 7, $561-566$

57 Cai, Y.; Liu, Y. A diol-functionalized ionic liquid: an efficient, simple, and recoverable "capture and release" reagent for aldehydes. Monatsh. Chem., 2008, 
$140,39-44$.

58 Muthayala, M. K.; Kumar, A. Ionic liquid-supported aldehyde: A highly efficient scavenger for primary amines. ACS Comb. Sci., 2011, 14, 5-9.

Dyson, P. J. Review: Synthesis of organometallics and catalytic hydrogenations in ionic liquids. Appl. Organomet. Chem., 2002, 16, 495-500.

60 Sawant, A. D.; Raut, D. G.; Darvatkar, N. B.; Salunkhe, M. M. Recent developments of task-specific ionic liquids in organic synthesis. Green Chem. Lett. Rev. 2011, $4,41-54$.

61 Yue, C.; Fang, D.; Liu, L.; Yi, T.-F. Synthesis and application of task-specific ionic liquids used as catalysts and/or solvents in organic unit reactions. $J$. Mol. Liq., 2011, 163, 99-121.

62 Miao, W.; Chan, T. H. Ionic-Liquid-Supported Synthesis: A Novel Liquid-Phase Strategy for Organic Synthesis. Acc. Chem. Res., 2006, 39, 897-908.

63 Baudequin, C.; Brégeon, D.; Levillain, J.; Guillen, F.; Plaquevent, J.-C.; Gaumont, A.-C. Chiral ionic liquids, a renewal for the chemistry of chiral solvents? Design, synthesis and applications for chiral recognition and asymmetric synthesis. Tetrahedron: Asymmetry, $\mathbf{2 0 0 5}$ 16, 3921-3945.

64 Ding, J.; Armstrong, D. W. Chiral ionic liquids: Synthesis and applications. Chirality, 2005, 17, 75 281-292.

Zhang, Q.; Zhang, S.; Deng, Y. Recent advances in ionic liquid catalysis. Green Chem., 2011, 13, 2619-2637.

66 Mehnert, C. P. Supported Ionic Liquid Catalysis. Chem. Eur. J., 2005, 11, 50-56.

67 Lee, J. W.; Shin, J. Y.; Chun, Y. S.; Jang, H. B.; Song, C. E.; Lee, S.-g. Toward Understanding the Origin of Positive Effects of Ionic Liquids on Catalysis: Formation of More Reactive Catalysts and Stabilization of Reactive Intermediates and Transition States in Ionic Liquids. Acc. Chem. Res., 2010, 43, 985-994.
68 Mancuso, A. J.; Brownfain, D. S.; Swern, D. Structure of the dimethyl sulfoxide-oxalyl chloride reaction product. Oxidation of heteroaromatic and diverse alcohols to carbonyl compounds. J. Org. Chem., 1979 $44,4148-4150$.

69 Mancuso, A. J.; Huang, S.-L.; Swern, D. Oxidation of long-chain and related alcohols to carbonyls by dimethyl sulfoxide "activated" by oxalyl chloride. $J$. Org. Chem., 1978, 43, 2480-2482.

70 He, X.; Chan, T. H. New non-volatile and odorless organosulfur compounds anchored on ionic liquids. Recyclable reagents for Swern oxidation. Tetrahedron, 2006, 62, 3389-3394.

71 Cheng, X. Y.; Li, K. F.; Wang, Q. J.; Wang, C. Y.; Ying, T. K. Oxidation of alcohols to aldehydes and ketones using selenium ionic liquid. Chin. Chem. Lett., 2012 $23,801-804$.

72 Merritt, E. A.; Olofsson, B. Diaryliodonium Salts: A Journey from Obscurity to Fame. Angew. Chem. Int. Ed., 2009, 48, 9052-9070.

73 Zhdankin, V. V.; Stang, P. J. Chemistry of Polyvalent Iodine. Chem. Rev., 2008, 108, 5299-5358.

Zhdankin, V. V.; Stang, P. J. Recent Developments in the Chemistry of Polyvalent Iodine Compounds. Chem. Rev., 2002, 102, 2523-2584.

Stang, P. J.; Zhdankin, V. V. Organic Polyvalent Iodine Compounds. Chem. Rev., 1996, 96, 1123-1178.

76 Ishiwata, Y.; Togo, H. Ion-supported PhI-catalyzed cyclization of $\mathrm{N}$-methoxy-2-arylethanesulfonamides with mCPBA. Tetrahedron Lett., 2009, 50, 5354-5357.

77 Kawano, Y.; Togo, H. Iodoarene-catalyzed one-pot preparation of 2,4,5-trisubstituted oxazoles from alkyl aryl ketones with mCPBA in nitriles. Tetrahedron, 2009, 65, 6251-6256.

78 Togo, H.; Akiike, J.; Yamamoto, Y. Efficient Conversion of Ketones to $\alpha$-Tosyloxyketones with m-Chloroperbenzoic Acid and p-Toluenesulfonic Acid in the Presence of Catalytic Amount of IL-Supported $\mathrm{PhI}$ in [emim]OTs. Synlett, 2007, 2168-2172. 
Koser, G. F.; Relenyi, A. G.; Kalos, A. N.; Rebrovic, L.; Wettach, R. H. One-step .alpha.-tosyloxylation of ketones with [hydroxy(tosyloxy)iodo]benzene. J. Org. Chem., 1982, 47, 2487-2489.

80 Sawamura, T.; Kuribayashi, S.; Inagi, S.; Fuchigami, T. Use of Task-Specific Ionic Liquid for Selective Electrocatalytic Fluorination. Org. Lett., 2010, 12, 644-646.

81 Qian, W.; Jin, E.; Bao, W.; Zhang, Y. Clean and selective oxidation of alcohols catalyzed by ion-supported TEMPO in water. Tetrahedron, 2006, 62, 556-562.

82 Qian, W.; Pei, L. Efficient and Highly Selective Oxidation of Sulfides to Sulfoxides in the Presence of an Ionic Liquid Containing Hypervalent Iodine. Synlett, 2006, 709-712.

83 Fang, C.; Qian, W.; Bao, W. A Mild and Clean Method for Oxidative Formation of Amides from Aldehydes and Amines. Synlett, 2008, 2529-2531.

Iinuma, M.; Moriyama, K.; Togo, H. Various oxidative reactions with novel ion-supported (diacetoxyiodo)benzenes. Tetrahedron, 2013, 69, 2961-2970.

Handy, S. T.; Okello, M. Homogeneous Supported Synthesis Using Ionic Liquid Supports: Tunable Separation Properties. J. Org. Chem., 2005, 70, 2874-2877.

Handy, S. T.; Okello, M. Fructose-derived ionic liquids: recyclable homogeneous supports. Tetrahedron Lett., 2003, 44, 8399-8402.

87 Handy, S. T. Greener Solvents: Room Temperature Ionic Liquids from Biorenewable Sources. Chem. Eur. J., 2003, 9, 2938-2944.

Bing Yang, J. Z., Dejian Zhao, Yazhen Wang, Hongbin Jia Efficient Synthesis of Various 4-Tosyloxy-2-substituted Phenols Using Pyridinium Salt-supported [Hydroxy(tosyloxy)iodo]benzene Reagent. Chem. Lett., 2013, 42, 930-932. of ionic liquid-supported hypervalent iodine reagent and its application as a 'catch and release' reagent for [small alpha]-substituted acetophenones. RSC Advances, 2014, 4, 14297-14303.

Zhang, B.; Zhao, X.; Wu, Q.; Guo, Y. Application of Diaryliodonium Salts in Arylation Reaction. Prog. Chem., 2013, 25, 1142-1148.

91 Kumar Muthyala, M.; Choudhary, S.; Pandey, K.; Shelke, G. M.; Jha, M.; Kumar, A. Synthesis of Ionic-Liquid-Supported Diaryliodonium Salts. Eur. J. Org. Chem., 2014, 2365-2370.

92 Shibuya, M.; Tomizawa, M.; Suzuki, I.; Iwabuchi, Y. 2-Azaadamantane N-Oxyl (AZADO) and 1-Me-AZADO: Highly Efficient Organocatalysts for Oxidation of Alcohols. J. Am. Chem. Soc., 2006, 128, 8412-8413.

93 Sheldon, R. A.; Arends, I. W. C. E.; ten Brink, G.-J.; Dijksman, A. Green, Catalytic Oxidations of Alcohols. Acc. Chem. Res., 2002, 35, 774-781.

94 Zhu, J.; Wang, P.-c.; Lu, M. Synthesis of novel magnetic silica supported hybrid ionic liquid combining TEMPO and polyoxometalate and its application for selective oxidation of alcohols. $R S C$ Advances, 2012, 2, 8265-8268.

95 Wu, X.-E.; Ma, L.; Ding, M.-X.; Gao, L.-X. TEMPO-Derived Task-Specific Ionic Liquids for Oxidation of Alcohols. Synlett, 2005, 607-610.

96 Liu, L.; Ma, J.; Sun, Z.; Zhang, J.; Huang, J.; Li, S.; Tong, Z. Supported task-specific ionic liquid catalyst for highly efficient and recyclable aerobic oxidation of benzyl alcohols. Can. J. Chem., 2010, 89, 68-71.

97 Fall, A.; Sene, M.; Gaye, M.; Gómez, G.; Fall, Y. Ionic liquid-supported TEMPO as catalyst in the oxidation of alcohols to aldehydes and ketones. Tetrahedron Lett., 2010, 51, 4501-4504.

98 Zhu, C.; Yoshimura, A.; Wei, Y.; Nemykin, V. N.; Zhdankin, V. V. Facile preparation and reactivity of bifunctional ionic liquid-supported hypervalent iodine reagent: a convenient recyclable reagent for catalytic 
oxidation. Tetrahedron Lett., 2012, 53, 1438-1444.

99 Vitz, J.; Mac, D. H.; Legoupy, S. Ionic liquid supported tin reagents for Stille cross coupling reactions. Green Chem., 2007, 9, 431-433.

100 Pham, P. D.; Legoupy, S. Organotin reagents supported on ionic liquid: highly efficient catalytic free radical reduction of alkyl halides. Tetrahedron Lett., 2009, 50, 3780-3782.

101 Louaisil, N.; Pham, P. D.; Boeda, F.; Faye, D.; Castanet, A.-S.; Legoupy, S. Ionic Liquid Supported Organotin Reagents: Green Tools for Stille Cross-Coupling Reactions with Brominated Substrates. Eur. J. Org. Chem., 2011, 2011, 143-149.

102 Dien Pham, P.; Vitz, J.; Chamignon, C.; Martel, A.; Legoupy, S. Stille Cross-Coupling Reactions with Tin Reagents Supported on Ionic Liquids. Eur. J. Org. Chem., 2009, 2009, 3249-3257.

103 Imura, Y.; Shimojuh, N.; Kawano, Y.; Togo, H. Novel preparation of ion-supported triphenylphosphines and their synthetic utility. Tetrahedron, 2010, 66, 3421-3426.

104 Imura, Y.; Shimojuh, N.; Moriyama, K.; Togo, H. Aza-Morita-Baylis-Hillman reaction with ion-supported Ph3P. Tetrahedron, 2012, 68, 2319-2325.

105 Shimojuh, N.; Imura, Y.; Moriyama, K.; Togo, H. Wittig reaction with ion-supported $\mathrm{Ph} 3 \mathrm{P}$. Tetrahedron, 2011, 67, 951-957.

106 Iranpoor, N.; Firouzabadi, H.; Azadi, R. A new diphenylphosphinite ionic liquid (IL-OPPh2) as reagent and solvent for highly selective bromination, thiocyanation or isothiocyanation of alcohols and trimethylsilyl and tetrahydropyranyl ethers. Tetrahedron Lett., 2006, 47, 5531-5534.

107 Iranpoor, N.; Firouzabadi, H.; Azadi, R. Diphenylphosphinite ionic liquid (IL-OPPh2): A solvent and ligand for palladium-catalyzed silylation and dehalogenation reaction of aryl halides with triethylsilane. J. Organomet. Chem., 2010, 695,
887-890.

108 Iranpoor, N.; Firouzabadi, H.; Azadi, R. Imidazolium-based phosphinite ionic liquid (IL-OPPh2) as Pd ligand and solvent for selective dehalogenation or homocoupling of aryl halides. $J$. Organomet. Chem., 2008, 693, 2469-2472.

109 Iranpoor, N.; Firouzabadi, H.; Azadi, R. An Imidazolium-Based Phosphinite Ionic Liquid (IL-OPPh2) as a Reusable Reaction Medium and PdII Ligand in Heck Reactions of Aryl Halides with Styrene and n-Butyl Acrylate. Eur. J. Org. Chem., 2007, 2007, 2197-2201.

110 Valizadeh, H.; Gholipour, H.; Mahmoudian, M. Phosphinite ionic liquid (IL-OPPh2) as a recyclable reagent for the efficient synthesis of coumarins under microwave irradiation conditions. J. Iran. Chem. Soc., 2011, $8,862-871$.

111 Mizuki Nakajima, K. Q., Nobuhisa Kobayashi, Quanxi Bao, Daisuke Tomida, and Chiaki Yokoyam Efficient Dehydration of Aldoximes to Nitriles Catalyzed by a Lewis Acid Ionic Liquid. Chem. Lett., 2011, 40, 396-397.

112 Muthyala, M. K.; Choudhary, S.; Kumar, A. Synthesis of Ionic Liquid-Supported Sulfonyl Azide and Its Application in Diazotransfer Reaction. J. Org. Chem., 2012, 77, 8787-8791.

113 Koguchi, S.; Nakamura, K. Ascorbic Acid Based Ionic Liquids: Recyclable and Efficient Catalytic Systems for the Huisgen Cycloaddition. Synlett, 2013, 24, 2305-2309.

114 Kim, D. W.; Song, C. E.; Chi, D. Y. New Method of Fluorination Using Potassium Fluoride in Ionic Liquid: Significantly Enhanced Reactivity of Fluoride and Improved Selectivity. J. Am. Chem. Soc., 2002, 124, 10278-10279.

115 Yadav, J. S.; Reddy, B. V. S.; Basak, A. K.; Venkat Narsaiah, A. [Bmim]PF6 and BF4 ionic liquids as novel and recyclable reaction media for aromatic amination. Tetrahedron Lett., 2003, 44, 2217-2220. 
116 Betti, C.; Landini, D.; Maia, A. Reactivity of anionic nucleophiles in ionic liquids and molecular solvents. Tetrahedron, 2008, 64, 1689-1695.

117 Landini, D.; Maia, A. Anion nucleophilicity in ionic liquids: a comparison with traditional molecular solvents of different polarity. Tetrahedron Lett., 2005, 46, 3961-3963.

118 Heidarizadeh, F; BeitSaeed, A.; Rezaee-Nezhad, E. Synthesis of 1,2-azidoalcohols from epoxides using a task-specific protic ionic liquid: 1-hydrogen-3-methylimidazolium azide. C. R. Chim., 2014, $17,450-453$.

119 Guy, R. G. In Syntheses and preparative applications of thiocyanates; John Wiley \& Sons, Ltd., 2010. pp 819-886

120 Kamal, A.; Chouhan, G. A task-specific ionic liquid [bmim]SCN for the conversion of alkyl halides to alkyl thiocyanates at room temperature. Tetrahedron Lett., 2005, 46, 1489-1491. 2-Hydroxy-N,N,N-tributylethanaminium thiocyanate as solvent and reagent for the preparation of alkyl thiocyanates. Tetrahedron Lett., 2007, 48, 7240-7242.

122 Yadav, L. D. S.; Patel, R.; Rai, V. K.; Srivastava, V. P. An efficient conjugate hydrothiocyanation of chalcones with a task-specific ionic liquid. Tetrahedron Lett., 2007, 48, 7793-7795.

123 Kumar, A.; Muthyala,

M.

K. 1-Butyl-3-methylimidazolium p-toluenesulfinate: a novel reagent for synthesis of sulfones and $\beta$-ketosulfones in ionic liquid. Tetrahedron Lett., 2011, $52,5368-5370$

124 Mi, X.; Luo, S.; Xu, H.; Zhang, L.; Cheng, J.-P. Hydroxyl ionic liquid (HIL)-immobilized quinuclidine for Baylis-Hillman catalysis: synergistic effect of ionic liquids as organocatalyst supports. Tetrahedron, 2006, 62, 2537-2544.

125 Mi, X.; Luo, S.; Cheng, J.-P. Ionic Liquid-Immobilized Quinuclidine-Catalyzed Morita-Baylis-Hillman
Reactions. J. Org. Chem., 2005, 70, 2338-2341.

126 Basavaiah, D.; Dharma Rao, P.; Suguna Hyma, R. The Baylis-Hillman reaction: A novel carbon-carbon bond forming reaction. Tetrahedron, 1996, 52, 8001-8062.

127 Singh, V.; Batra, S. Advances in the Baylis-Hillman reaction-assisted synthesis of cyclic frameworks. Tetrahedron, 2008, 64, 4511-4574.

128 Bates, E. D.; Mayton, R. D.; Ntai, I.; Davis, J. H. CO2 Capture by a Task-Specific Ionic Liquid. J. Am. Chem. Soc., 2002, 124, 926-927.

129 Robichaud, A.; Nait Ajjou, A. First example of direct reductive amination of aldehydes with primary and secondary amines catalyzed by water-soluble transition metal catalysts. Tetrahedron Lett., 2006, 47, 3633-3636.

130 Miriyala, B.; Bhattacharyya, S.; Williamson, J. S. Chemoselective reductive alkylation of ammonia with carbonyl compounds: synthesis of primary and symmetrical secondary amines. Tetrahedron, 2004, 60, 1463-1471.

131 Muthayala, M. K.; Kumar, A. Ionic Liquid-Supported Aldehyde: A Highly Efficient Scavenger for Primary Amines. ACS Comb. Sci., 2012, 14, 5-9.

132 Huang, Q.; Zheng, B. Facile Synthesis of Benzaldehyde-Functionalized Ionic Liquids and Their Flexible Functional Group Transformations. Organic Chemistry International, 2012, 5.

133 Gunaratne, H. Q. N.; Nockemann, P.; Seddon, K. R. Ionic liquids for efficient hydrogen sulfide and thiol scavenging. Green Chem., 2014, 16, 2411-2417.

134 Kang, L.-Q.; Cai, Y.-Q.; Peng, Y.-Q.; Ying, X.-L.; Song, G.-H. Silica-supported sulfonic acid-functionalized ionic liquid coated with [bmim][PF6] as a scavenger for the synthesis of amides. Mol. Divers., 2011, 15, 109-113. 